\title{
The role of electricity storage and hydrogen technologies in enabling global low-carbon energy transitions
}

Journal submission to Applied Energy

Keywords:

Storage technologies

Hydrogen technologies

Variable renewable energy integration

Energy system transition

Integrated assessment modelling 


\section{Abstract}

Previous studies have noted the importance of electricity storage and hydrogen technologies for enabling large-scale variable renewable energy (VRE) deployment in long-term climate change mitigation scenarios. However, global studies, which typically use integrated assessment models, assume a fixed cost trajectory for storage and hydrogen technologies; thereby ignoring the sensitivity of VRE deployment and/or mitigation costs to uncertainties in future storage and hydrogen technology costs. Yet there is vast uncertainty in the future costs of these technologies, as reflected in the range of projected costs in the literature. This study uses the integrated assessment model, MESSAGE, to explore the implications of future storage and hydrogen technology costs for low-carbon energy transitions across the reported range of projected technology costs. Techno-economic representations of electricity storage and hydrogen technologies, including utility-scale batteries, pumped hydro storage (PHS), compressed air energy storage (CAES), and hydrogen electrolysis, are introduced to MESSAGE and scenarios are used to assess the sensitivity of long-term VRE deployment and mitigation costs across the range of projected technology costs. The results demonstrate that large-scale deployment of electricity storage technologies only occurs when techno-economic assumptions are optimistic. Although pessimistic storage and hydrogen costs reduce the deployment of these technologies, large VRE shares are supported in carbon-constrained futures by the deployment of other low-carbon flexible technologies, such as hydrogen combustion turbines and concentrating solar power with thermal storage. However, the cost of the required energy transition is larger. In the absence of carbon policy, pessimistic hydrogen and storage costs significantly decrease VRE deployment while increasing coal-based electricity generation. Thus, R\&D investments that lower the costs of storage and hydrogen technologies are important for reducing emissions in the absence of climate policy and for reducing mitigation costs in the presence of climate policy.

List of Acronyms:

VRE: variable renewable energy

PHS: pumped hydro storage

CAES: compressed air energy storage

IAM: integrated assessment model 
MESSAGE: model for energy supply strategy alternatives and their general environmental impact

RLDC: residual load duration curve

H2: hydrogen

CT: combustion turbine

GHG: greenhouse gas 


\section{Introduction}

During the period from 1990 to 2010, variable renewable energy (VRE) deployment increased rapidly, with average annual global primary energy growth rates of $44 \%$ and $25 \%$ for solar and wind, respectively [1] [2]. This largescale deployment has been motivated by a number of drivers, including government subsidies, rapidly declining investment costs, energy security concerns, and growing global consensus around climate change risks [3] [4]. Future scenarios of the global energy system suggest an even larger role for renewable energy over the next century, particularly if climate policy is introduced. Six global integrated assessment models (IAMs) indicate that solar and wind energy is projected to comprise $35-63 \%$ of total electricity generation in 2050 and $47-86 \%$ in 2100 if policies that limit warming in 2100 to 2 degrees Celsius above pre-industrial levels are introduced [5]. However, integration of renewable electricity sources, with their inherently variable nature, introduces novel challenges, both in terms of real-world deployment and model implementation.

VRE temporal variability, forecast uncertainty, and location-dependence prompt accompanying integration costs in terms of short-term balancing services, firm reserve capacity, thermal plant operational flexibility, VRE curtailment, and transmission expansion [6]. The increased flexibility required to maintain grid balance with large-scale VRE deployment can be achieved through a number of strategies or technologies such as flexible generation, VRE curtailment, electricity storage, hydrogen technologies, and demandside management [7]. The role of storage technologies for integrating large shares of renewables are typically assessed using temporallyresolved electricity dispatch models, with the intention of quantifying storage requirements [8] [9], assessing storage profitability in power markets [10], [11], [12], or forecasting storage deployment in capacity expansion models [13], [14], [15]. However, it is also important to account for these challenges and their associated costs when assessing the long-term global energy system transitions needed to mitigate climate change.

The models typically used to assess these transitions are global IAMs, which endogenously consider cost and performance trade-offs among energy supply and end-use technologies to provide insights into the future development of energy systems and the associated investments required to meet long-term climate targets [16]. Given their technological detail and broad spatial and temporal scope, IAMs have been effective tools for assessing long-term global energy and 
emission scenarios and have been widely used to identify mitigation challenges, emission trajectories, and the implications of policy for meeting climate change targets [16]. However, for computational reasons, the broad scope has necessitated compromises in spatial and temporal resolution, which poses a challenge for representing renewable energy resources, which typically exhibit large spatial and temporal heterogeneity. Consequently, the variability of renewable generation and its associated integration challenges must be parameterized indirectly in IAMs. Although several global IAMs have recently addressed this concern by improving their representation of the technologies and investments required to integrate large VRE shares [5] [17], no previous study has used a global IAM to assess the sensitivity of future VRE deployment to uncertainties in the future costs of storage and hydrogen technologies, which previous studies suggest will be important technologies for integrating VRE [13].

In this study, we assess the role of electricity storage and hydrogen technologies in enabling global low-carbon energy transitions using the global IAM, MESSAGE (Model for Energy Supply Strategy Alternatives and their General Environmental Impact), which is a partialequilibrium optimization model with a detailed bottom-up representation of energy transformation technologies (see supplementary material for more information) [18] [19]. In previous research, the representation of system adaptations for integrating VRE was improved through the introduction of two constraints to ensure sufficient capacity reserves and system flexibility [20] and through the parameterization of VRE curtailment, non-VRE flexibility requirements, and wind and solar PV capacity values based on region-specific residual load duration curves (RLDC) [21] . Using this updated representation, Johnson et al. (2017) highlight the importance of electricity storage and hydrogen technologies in enabling high-VRE penetration scenarios, particularly in carbon-constrained scenarios. However, previous studies assumed a single 'generic' storage technology with a relatively small cost ranging from $\$ 800 / \mathrm{kW}$ in 2010 to $\$ 600 / \mathrm{kW}$ in 2100 for 12 hours of storage. Yet, there are several technologies that can provide bulk electricity storage and grid services, including hydrogen technologies, and there is uncertainty regarding their future costs and deployment potentials [22]. Thus, future VRE deployment and/or the costs of climate change mitigation may depend on how storage and hydrogen technologies develop.

This paper contributes modeling methods and policy insights regarding the roles of electricity storage and hydrogen technologies for integrating large shares of renewable energy. We improve 
upon the representation of electricity storage in the MESSAGE model by implementing several storage technology profiles to replace the single existing 'generic' technology profile. The approach and parameterization described herein could inform improved storage technology representations in other long-term energy-economic models. With these updated technologies, we conduct a scenario-based assessment of how VRE deployment rates are impacted across a range of plausible storage technology cost trajectories. Given the substantial role of VRE resources in low-carbon energy scenarios as well as the importance of electricity storage and hydrogen technologies for enabling VRE deployment, this analysis contributes important insights regarding the techno-economic conditions that may facilitate or impede low-carbon futures. While previous reports have published near-term storage technology assessments [23] [24] [25], to our knowledge no previous analysis has assessed the impact of storage and hydrogen cost trajectories on long-term global low-carbon energy transitions. More specifically, storage forecasting assessments generally extract historical trends or perform expert surveys, and are often limited to a short ( $<25$ year) forecasting horizon and small geographic area. Further, the techno-economic assessments of hydrogen and storage technologies provide valuable information on the state-of-the-art, but do not provide insight into the system-level impacts of cost uncertainties. In contrast, the use of an integrated assessment model enables an exploration of how these cost uncertainties may impact future energy investment decisions and the consequences for long-term climate change mitigation strategies and costs. Each storage technology profile is parameterized through a literature review, focusing on the grid services that they provide (Section 2), as well as the reported ranges for their future costs and deployment potentials (Section 3). These ranges are represented in the integrated assessment model MESSAGE using ten distinct scenarios (Section 4). Using these scenarios, we assess the sensitivities of VRE deployment and climate change mitigation costs across the range of projected electricity storage and hydrogen technology costs (Sections 5). Finally, the limitations associated with this analysis (Section 6) and key conclusions (Section 7) are discussed.

\section{Storage Technology Services}

The electricity system services provided by storage technologies are represented by a series of constraints in MESSAGE that account for hourly-daily and seasonal curtailment and ensure sufficient firm capacity and flexible generation as VRE deployment increases [20] [21]. Hydrogen and storage technologies with distinct technical characteristics are included in the 
model that can mitigate curtailment and/or provide firm capacity and system flexibility.

VRE curtailment in MESSAGE has been parameterized using regional residual load duration curves (RLDC) for distinct wind/solar PV mixes, which represent net load after VRE generation has been subtracted from the total load [21][26]. The average total curtailment is split into shortterm curtailment (<24 hours) and seasonal curtailment[21]. Pumped hydro, compressed air energy storage, utility-scale batteries, and hydrogen electrolysis enable load-following and ramping services that can mitigate curtailment at the hourly-daily timescale.

Seasonal variations in electricity demand have historically been accommodated by gas, oil, and coal fuel storage. At high VRE penetrations, the seasonal variations in renewable resources combined with smaller shares of conventional generators may require additional seasonal electricity storage to balance the grid. As such, at high VRE penetration levels, VRE curtailment is observed, even with an entirely flexible electricity system and up to 24 hours of electricity storage [27]. This seasonal VRE curtailment can only be mitigated in MESSAGE through hydrogen electrolysis systems with long-term hydrogen storage capacities.

The capacity reserve constraint ensures a minimum level of firm capacity on the electricity system to meet the system's peak load and to handle contingency events. Storage as well as hydrogen and conventional generation technologies are considered dispatchable and thus contribute their nameplate capacity to the system's firm capacity requirement. On the other hand, only a fraction of VRE nameplate capacity is considered firm. This fraction, known as capacity value, diminishes with increasing VRE share[21].

MESSAGE's operating reserve constraint ensures that the electricity system has sufficient flexibility to ramp with variations and uncertainty in demand and VRE supply. The minimum fraction of flexible generation from non-VRE generators increases with VRE penetration until it saturates when $100 \%$ of non-VRE generation must be flexible. The fraction of generation that is considered flexible depends on the technology and whether the asset is operating in baseload or flexible mode (see Johnson et al., 2017). Generation from storage technologies, hydrogen combustion turbines, and utility-scale fuel cells is considered entirely flexible and thus is an important form of low-carbon system flexibility under increasing VRE shares. 


\section{Storage Technology Profiles}

Currently, electricity storage deployment is limited, with global installed storage of $110 \mathrm{GW}$, $90 \%$ of which is pumped hydro storage [28]. However, the energy storage market is expected to increase 20-fold between 2010 and 2020, largely driven by increasing variable renewable generation [28]. The original MESSAGE implementation included a single 'generic' storage technology, based on compressed air energy storage, which addressed short-term curtailment, provided firm capacity and system flexibility, and had an efficiency of $80 \%$, investment costs ranging from $\$ 800 / \mathrm{kW}$ in 2010 to $\$ 600 / \mathrm{kW}$ in 2100, and unlimited deployment potential [21]. In the proposed implementation, four commercial or pre-commercial development technologies, with a range of integration services are modeled: pumped hydro storage (PHS), compressed air energy storage (CAES), utility-scale batteries, and hydrogen electrolysis with seasonal storage. The following sections detail the techno-economic characteristics of the four storage technologies, which are summarized in Table 2. The focus of storage technology services in this analysis is limited to bulk electricity balancing; thus, 12 hours of storage capacity was assumed in estimating the costs in the following section. However, the range in costs presented below reflects differences in storage capacity, as well as uncertainty in future costs and alternative application contexts.

\subsection{Batteries}

Batteries have been designed using a variety of chemistries, including sodium-sulphur, vanadium redox flow, lead-acid, lithium ion, and lithium polymer. Some battery chemistries rely on the availability of specialized materials, such as lithium, which may have a limited economically recoverable resource [29]. Other technologies, such as sodium-sulfur and advanced lead acid, exhibit impaired performance beyond a number of charge and discharge cycles. With limited utility-scale deployments to date, lithium ion and advanced lead-acid battery installations for fast frequency regulation purposes are currently considered to be in the demonstration stage [30]. As such, their technical and economic characteristics and the resulting development pathways over the next century are difficult to forecast. Given this uncertainty, a 'generic battery' technology was modeled using the best information currently available. 
Battery storage systems with relatively large power and energy ratings, such as sodium-sulfur and advanced lead-acid with 50 - 100 MW power capacities and 4 - 6-hour storage reservoirs, can provide hourly-daily VRE integration services [30] with fast dispatchability [29].

According to the Electric Power Research Institute (EPRI), lithium-ion batteries for fast frequency regulation currently cost between $1,085-1,550 \$ / \mathrm{kW}$, or 4340 - $6200 \$ / \mathrm{kWh}$ for 0.25 hour of storage duration [30]. The cost for advanced lead-acid batteries for fast frequency regulation is currently between $950-1,590 \$ / \mathrm{kW}$, or 3800 - $6360 \$ / \mathrm{kWh}$ given a storage duration of 0.25 hour [30]. In both cases, the costs are based on a reported depth of discharge [30]. Other sources report lithium-ion costs of 1200-4000 \$/kW [23], [31], [32], [25], [33]. Based on cost and shipment volumes for Li-ion batteries between 1997 and 2003, EPRI calculated a learning rate of 30\% [30]. Projecting this learning rate forward, EPRI estimates that battery costs could decline quickly to less than $1000 \$ / \mathrm{kW}$ [28]. Within MESSAGE, it has been assumed that battery technology costs will range from $1,700 \$ / \mathrm{kW}$ (optimistic) to $5,100 \$ / \mathrm{kW}$ (pessimistic) at the beginning of the analysis period and from $800 \$ / \mathrm{kW}$ (optimistic) to 2,400 $\$ / \mathrm{kW}$ (pessimistic) by 2100. These costs have been adjusted from those found in the literature to account for 12 hours of energy storage capacity.

Batteries have efficiencies ranging from as low as $75 \%$ for the least efficient advanced lead-acid to over $92 \%$ for the most efficient Li-ion. In MESSAGE, an average efficiency of $75 \%$ and a lifetime of 10 years [34] are assumed. No theoretical limit on the deployment of batteries is imposed in the model.

\subsection{Pumped Hydro Storage}

Pumped hydro storage (PHS) is currently the most mature energy storage technology. The majority of PHS capacity in the USA and Europe was built in the 1960s to 1980s, in part due to the growth in nuclear energy after the oil crisis [35]. In the 1990s, fewer facilities were developed in the USA and Europe due to a saturation of the best available sites and a decline in nuclear growth [35]. However, interest in PHS is growing with VRE deployment [35], precipitating PHS proposals of 7.4 GW in Europe [35], 4.8 GW in Japan [35], 50 GW in China [36], and $22 \mathrm{GW}$ in the United States [37]. 
Typical pumped hydro storage facilities have between 6 and 12 hours of storage and power capacities ranging from 280 to 1,400 MW [30], enabling daily energy arbitrage [29] and hourlydaily VRE curtailment mitigation. Three distinct types of pumped hydro storage have been included in MESSAGE: (1) retrofits using two existing reservoirs, (2) retrofits using one existing reservoir, and (3) greenfield sites using an underground reservoir. Each of these technologies has been implemented with unique costs and potential deployment assumptions, as described below. Given the large potential for retrofitting existing hydropower reservoirs to include pumping capability [38], conventional (above-ground) greenfield construction is excluded as an option in MESSAGE.

Gimeno-gutierrez et al. estimate that 198 GWh of PHS capacity or 17 GW of generating capacity (assuming 12 hours of storage) can be accessed by connecting two existing reservoirs and hydropower facilities in Europe [38]. In the absence of similar studies in other regions, we estimate that a maximum of 5\% of hydropower potential could be converted into PHS by connecting two existing reservoirs in all model regions, based on the Gimeno-gutierrez et al. European estimation.

By including areas in which a new reservoir could be built and linked to a single existing reservoir within a $5 \mathrm{~km}$ distance, the realizable PHS potential capacity increases to 9,600 GWh (800 GW assuming 12 hours of storage) in western Europe and $600 \mathrm{GWh}$ (50 GW) in eastern Europe [38]. The most recent estimate of PHS potential in the United States (conducted in the 1980s) indicates a theoretical potential capacity of over $1000 \mathrm{GW}$ and an available (realizable) potential of $180 \mathrm{GW}$. The realizable potential of one-reservoir PHS retrofits as a fraction of economically feasible hydropower potentials in the United States, eastern Europe, and western Europe are $180 \%, 100 \%$, and 250\%, respectively. In the absence of information in other world regions, a proxy metric is developed to estimate the conventional PHS potential as a function of economic hydropower potential, using the ratios provided above: 200\% of installed hydropower capacity in each region and time period.

Underground PHS faces fewer siting restrictions than retrofitted PHS since it only requires lowvalue flatland on the surface and competent rock at the reservoir depth. Sites with these characteristics are abundant [39]. In the United States, there are currently 36 proposed PHS projects, of which approximately one quarter propose to use an underground cavern as one of the 
two reservoirs [40]. In MESSAGE, no theoretical upper limit is imposed on the availability of potential sites for underground PHS. Rather, underground PHS deployment is bound by its high cost relative to other PHS technologies.

Each of the three PHS technologies has significantly different costs due to their varying construction requirements. Published cost estimates for PHS vary widely from 500 - 4600 \$/kW [22], however numerous studies report a range of 600 - $2000 \$ / \mathrm{kW}$ [23] [31], [32], [25], [33]. Studies that report a single value tend towards 1000 \$/kW [41]. The Electric Power Research Institute reviewed investment costs for existing and planned greenfield PHS projects globally and developed an equation that relates average investment cost as a function of capacity (EPRI, 2011). Although historical and proposed project costs range between $200 \$ / \mathrm{kW}$ and $2500 \$ / \mathrm{kW}$, the cost equation suggests that, on average, investment costs decline from $1300 \$ / \mathrm{kW}$ to 1000 $\$ / \mathrm{kW}$ as the capacity of a project increases

The retrofitted PHS installations represented in MESSAGE utilize at least one existing reservoir and thus have smaller investment costs than greenfield projects. Although PHS could improve the utilization of existing hydropower capacity, we assume that existing turbines are well-utilized during peak load and thus supplemental turbines are required to exploit PHS potential fully. The two-reservoir retrofit requires the construction of supplemental hydro turbines, a penstock, and pumping equipment, while the one-reservoir retrofit also requires the construction of an upper or lower reservoir [37]. Krajačić et al. (2013) provide disaggregated cost estimates for PHS components, including the hydro turbines, pumps, penstock, reservoirs, grid connection, control system, and equipment transportation. These disaggregated costs are used to estimate average investment costs for retrofitted PHS facilities. The investment cost of a two-reservoir retrofit PHS is estimated to range from $650 \$ / \mathrm{kW}$ (optimistic) to $1950 \$ / \mathrm{kW}$ (pessimistic), and a onereservoir retrofit is estimated to range from $800 \$ / \mathrm{kW}$ (optimistic) to $2400 \$ / \mathrm{kW}$ (pessimistic).

In some cases, underground PHS could use an existing underground cavity as the lower reservoir, but such site availability may be limited. Tam et al. summarized the cost estimates from five underground PHS studies that were conducted in the 1960s-80s, ranging from 200 544 \$/kW in 1978 dollars or 900 - 2400 \$/kW in 2014 dollars [43]. More recently Pickard estimated 5.1 G\$US for a 2 GWd system [39], based on Gordon's methodology which estimated 5.4 G\$US for a 2 GWd system [44]. These estimates equate to 106 - 112 \$/kWh or 1272 - 
1350\$/kW for 12 hours of storage. Madlener et al. developed an underground PHS cost curve for increasing head heights using abandoned coal mines and an NREL estimate for greenfield PHS [45], and concluded with a cost of $253 \mathrm{EUR} / \mathrm{kWh}$ for a $1000 \mathrm{~m}$ head, which equates to 3792 $\$ / \mathrm{kW}$ for 12 hours of storage, and a 0.8 exchange rate to USD [46]. In this analysis, investment costs for underground PHS are estimated to range from $1250 \$ / \mathrm{kW}$ (optimistic) to 3750\$/kW (pessimistic). All PHS investment costs are assumed to remain constant over time since the technology components are mature and therefore have a limited learning rate [28].

Large PHS efficiency estimates range from 70\% to 85\% [22] [30] [28]; the proposed MESSAGE implementation assumes an 80\% efficiency and 50 years of plant life.

\subsection{Compressed Air Energy Storage}

Compressed air energy storage (CAES) facilities compress air in an underground cavity or in an above ground tank by consuming electricity during overproduction periods for subsequent use in a gas or hydrogen turbine. The pre-compression of air (with electricity) reduces the natural gas or hydrogen fuel requirements by approximately two-thirds [47]. CAES facilities are well-suited to perform bulk energy arbitrage on daily cycles and reduce hourly-daily VRE curtailment [29], with 8-20 hours of storage capacity at a rated power capacity of 135- 180 MW [30].

CAES facilities require appropriate geology to accommodate the underground storage reservoir, which could include a salt dome, bedded salt, hard rock, or porous rock formation [48]. Analyses of the United States have shown that over $75 \%$ of the country has geologic conditions that are potentially viable for underground air storage [49]. Further, analyses in Europe have identified the coincidence of dispersed domal formations, which are favorable for CAES development, with high-quality wind resources [50]. While such studies are promising, their macro scale does not provide adequate detail to fully analyze their suitability for project development [49]. Detailed site-specific analyses would be required for an accurate estimation. Further, each of these geologies, while potentially appropriate, have distinct availability and cost characteristics. Bedded salt, hard rock, and porous rock geologies are widely available throughout the United States, but bedded salt and hard rock geologies are expensive while porous rock formations are inexpensive [48]. Solution mining of salt deposits, as well as disused mines, also have favorable economics when compared to conventional mining [51]. In some cases, existing mines could be utilized, as with the proposed Norton CAES plant [49]. The two existing commercial CAES 
plants use salt domes as the underground reservoir [48], which may be the most straightforward to develop and operate, due to well-established solution mining techniques [49]. Due to the large availability of suitable sites [52] [48], albeit at a range of costs, no upper bound for CAES site availability was imposed in MESSAGE.

Published CAES cost estimates vary widely: 351 \$/kW in porous rock, 450 \$/kW in a salt mine, or $710 \$ / \mathrm{kW}$ in hard rock, each for ten hours of storage [53]. Similarly, Succar and Williams estimate a typical cost of $600 \$ / \mathrm{kW}$ for 10 hours of storage [48]. For 20 hours of storage, EPRI estimates a CAES cost of 1150 \$/kW [30]. The type of rock formation impacts the underground cavity excavation cost, ranging from $0.10 \$ / \mathrm{kWh}$ for a porous rock formation to $30 \$ / \mathrm{kWh}$ for excavation of a hard rock formation [54] [53]. More recent analysis report a similar range for compressed air storage: 0.10 EUR/kWh in porous rock, 1.01 EUR/kWh in solution-mined salt caverns, 9.71 EUR/kWh in dry-mined salt caverns, 9.71 EUR/kWh in abandoned mines, and 29.55 EUR/kWh in rock caverns from excavation [55]. Overall cost estimates accounting for all types of CAES facilities range from 400 - 800 \$/kW [56] [23] [31], [32], [25], [33], 500 - 1500 $\$ / \mathrm{kW}$ [22], 400-1000 \$/kW [24], $910 \mathrm{EUR} / \mathrm{kW}$ [57], and 1075 \$/kW [41] . Costs in the range of 325 - 975 \$/kW for gas CAES and 350 - 1050 \$/kW for hydrogen CAES are assumed in this analysis.

CAES facilities use both electricity and natural gas as inputs and electricity is the output. Typical ratios of these inputs and outputs, which are used in MESSAGE are as follows: $0.718 \mathrm{kWh}$ electricity input, $4649 \mathrm{~kJ}$ natural gas input, and $1.026 \mathrm{kWh}$ electricity output [58]. This configuration corresponds to an electricity ratio (electricity produced for electricity consumed) of 1.43, and an overall energy ratio (electricity produced for electricity and gas consumed) of 51\%. These ratios are consistent with other studies which report electricity ratios of between 1.25 to 1.6 [54]. Alternatively, the CAES configuration can be described by the heat rate, which is the ratio of natural gas fuel burned per unit of electricity generated. Typical CAES heat rate values range from 4.19 GJ/MWh [59] to 4.5 GJ/MWh [58].

The greenhouse gas emissions from gas CAES electricity production is calculated using the ratio of the natural gas input for the CAES facility compared to a conventional natural gas facility per unit of electricity output. A plant life of 30 years is assumed. 


\subsection{Hydrogen Electrolysis and Storage}

There are several technologies that convert electricity to hydrogen including microbial electrolysis [60] and water electrolysis [61]. While water electrolysis is a commercially available technology with near-term deployment potential, biological pathways are in the development phase and have yet to be deployed commercially [62]. As a result, this analysis only considers hydrogen production through water electrolysis as a means to mitigate hourlydaily curtailment as well as seasonal curtailment when coupled with long-term hydrogen storage. The hydrogen produced via electrolysis can then be transported and stored for subsequent electricity production using a hydrogen turbine or fuel cell or used as a transportation fuel. Alternatively, the model allows up to $15 \%$ of hydrogen by volume to be mixed into the natural gas system [63]. When combined with long-term storage, hydrogen electrolysis can provide seasonal flexibility. The volume of cavity or tank to store hydrogen gas can be much smaller than that for compressed air, due to hydrogen's higher energy density. Thus, on an energy basis, the underground reservoir costs for hydrogen storage are smaller than for compressed air storage [54], making it well-suited for seasonal energy storage applications [64].

Geologic storage of hydrogen gas in underground cavities is similar to that of compressed air storage, including man-made salt caverns or deep porous formations [65]. Several studies have demonstrated the availability of underground hydrogen storage in Northern Germany [66], Poland [67], and Romania [68], as well as the technical feasibility of hydrogen storage generally [69]. However, the availability of hydrogen storage options near large cities causes large cost disparities [70]. The costs of geologic hydrogen storage are based on CAES geologic storage and adjusted for their respective energy densities [54]. Cost estimates range from $0.002 \$ / \mathrm{kWh}$ for naturally occurring porous rock formations from depleted gas or oil fields to $0.02 \$ / \mathrm{kWh}$ for solution mined salt caverns and $0.30 \$ / \mathrm{kWh}$ for geologic storage [54]. Similarly, hydrogen storage investment costs have been estimated as $0.002 \mathrm{EUR} / \mathrm{kWh}$ in porous rock, $0.02 \mathrm{EUR} / \mathrm{kWh}$ in solution-mined salt caverns, $0.14 \mathrm{EUR} / \mathrm{kWh}$ in dry-mined salt caverns, $0.14 \mathrm{EUR} / \mathrm{kWh}$ in abandoned mines, $0.25 \mathrm{EUR} / \mathrm{kWh}$ in geologic $\mathrm{H} 2$ storage, and $0.41 \mathrm{EUR} / \mathrm{kWh}$ in rock caverns from excavation [55]. These cost estimates are consistent a more recent analysis of large cavern (500,000 $\mathrm{m}^{3}$ ) hydrogen storage investment costs falling from $280 \mathrm{EUR} / \mathrm{MWh}$ currently to 273 EUR/MWh in 2025 and 186 EUR/MWh $\mathrm{H}_{2}$ in 2050 [66]. For seasonal storage applications, the facility must accommodate electricity overproduction for half of the year, assuming a seasonal 
full-cycling routine. This results in capital costs for the hydrogen storage facility ranging from 2 $\$ / \mathrm{kW}$ for naturally occurring porous rock formations to $447 \$ / \mathrm{kW}$ for hard rock caverns created by excavating [54]. For the purposes of MESSAGE, a cost of 92-276 $\$ / \mathrm{kW}$ (corresponds to 0.15 $\$ / \mathrm{kWh}$ ) is added to the standard electrolyzer cost to account for the additional costs of long-term storage. Electrolyzer costs vary depending on their type, the deployment timeframe, and the reference. Alkaline electrolysis has costs of $1000 \mathrm{EUR} / \mathrm{kW}$ [71] to $1400 \mathrm{EUR} / \mathrm{kW}$ [55] today, with a potential future cost of $500 \mathrm{EUR} / \mathrm{kW}$ [71]. Solid oxide electrolysis has a similar future cost potential of $590 \mathrm{EUR} / \mathrm{kW}$ by 2020 [55]. PEM electrolyzers have a current cost of 2000 EUR/kW [71], with a near-term potential cost of $932 \mathrm{EUR} / \mathrm{kW}$ in 2025 [66] and $334 \mathrm{EUR} / \mathrm{kW}$ in 2050 [66]. Generic electrolysis costs are estimated at $1500 \$ / \mathrm{kW}$ under business as usual assumptions [72] and $740 \$ / \mathrm{kW}$ under optimistic assumptions [72]. In MESSAGE, the cost of the standard electrolyzer declines from $830 \$ / \mathrm{kW}$ at present to between $171 \$ / \mathrm{kW}$ (optimistic) and $512 \$ / \mathrm{kW}$ (pessimistic) in 2100. Hydrogen electrolysis with seasonal storage is $1014 \$ / \mathrm{kW}$ at present and varies from $263 \$ / \mathrm{kW}$ (optimistic) to $788 \$ / \mathrm{kW}$ (pessimistic) by 2100 . Analogous to CAES, no upper bound is imposed on the availability of salt deposits, oil and gas fields, and sedimentary basins [54].

The hydrogen storage facility efficiency includes losses in both the electrolyzer and hydrogen storage facility $(0.5 \%)$. The net efficiency of the electrolyzer with seasonal storage increases from $62 \%$ (2010) to $73 \%$ (2100), to account for projected improvements.

\subsection{Hydrogen Fuel Cells and Combustion Turbines}

There are several fuel cell configurations, including alkaline, proton exchange, direct methanol, phosphoric acid, molten carbonate, and solid oxide [73]. Stationary proton exchange membrane (PEM) fuel cells are appropriate for this analysis due to their low operating temperature, which enables frequent cycling on and off [54]. PEM fuel cells combine hydrogen, produced through electrolysis, and oxygen from the air to generate electricity and water through oxidationreduction.

There is a wide range of hydrogen fuel cell costs reported in the literature, depending on size and application. In the early 2000s, costs ranged from $2000 \$ / \mathrm{kW}$ to almost 16,000 $\$ / \mathrm{kW}$ [54]. More recently, fuel cell costs have dropped in cost, ranging from 434 - 3,000 \$/kW [54], 500 - 1500 $\$ / \mathrm{kW}$ [74], $500-3000 \$ / \mathrm{kW}$ [24], $800 \$ / \mathrm{kW}$ under optimistic assumptions and $2000 \$ / \mathrm{kW}$ 
under business as usual assumptions [72], or 2,700 EUR/kW [75]. The capital costs and learning rates of different fuel cell types also differ: $2320 \mathrm{EUR} / \mathrm{kW}$ (2013) to $250 \mathrm{EUR} / \mathrm{kW}$ (2030) for PEM fuel cells, 1200 - 3000 EUR/kW (2013) to 370-925 EUR/kW (2030) for alkaline fuel cells, and $6000 \mathrm{EUR} / \mathrm{kW}$ (2013) to $500 \mathrm{EUR} / \mathrm{kW}$ (2030) for solid oxide fuel cells [76].

Moreover, fuel cell efficiencies have been improving, and values have been reported as $47 \%$ 58\% [54], 20\%-50\% [74], and 50\% [73]. Hydrogen fuel cells currently have an estimated life of 20,000 charge and discharge cycles [74].

In MESSAGE, hydrogen fuel cells are expected to continue to drop in price, from 3,000 $\$ / \mathrm{kW}$ at the beginning of the analysis period to $217 \$ / \mathrm{kW}$ (optimistic) or $651 \$ / \mathrm{kW}$ (pessimistic) by 2100 . Efficiencies are also expected to improve from $47 \%$ currently to $58 \%$ by 2100 , and utility-scale fuel cells are assumed to have a 20-year lifetime, assuming an average load factor of $35 \%$.

MESSAGE also includes hydrogen combustion turbines for which costs are assumed to decrease from $318 \$ / \mathrm{kW}$ currently to $289 \$ / \mathrm{kW}$ in 2100 . Combustion turbines were not included in the sensitivity analysis since the technology is well established. The hydrogen combustion turbine is assumed to have a $40 \%$ efficiency, $43 \%$ load factor, and 30-year lifetime. Unlike electrolyzers that convert electricity to hydrogen and thus can help mitigate curtailment, fuel cells and combustion turbines generate electricity from hydrogen and thus only provide flexibility and firm capacity services.

\section{Scenario Design}

The analysis uses ten scenarios to explore the implications of storage technology sensitivities for VRE deployment and climate change mitigation. Two policy scenarios (summarized in Table 1) explore the implications for VRE deployment with and without a carbon tax. In contrast to the 'Baseline' scenario, in which the electricity sector develops without a carbon price, the Tax30 scenario imposes a $30 \$ /$ tonne $\mathrm{CO}_{2}$ (2005USD) tax starting in the 2021 - 2030 time frame that increases by 5\% per year throughout the century. These alternative carbon mitigation policies enable the exploration of the roles of storage and hydrogen technologies in electricity grids with different VRE penetrations and carbon intensities. For each policy scenario, five scenarios explore the sensitivity of long-term energy transitions across the range of technology costs and potentials as listed in Table 1. The techno-economic characteristics of each storage technology, 
including capital investment costs, technical potentials, efficiencies, and storage service characteristics, were modeled according to the discussion in the previous sections, and are summarized in Table 2.

The "optimistic" assumptions include a 50\% technology cost decrease and storage potential increase (summarized by the 'low cost' and 'high potential' columns in Table 2 and Figure 1). The "pessimistic" assumptions include a 50\% technology cost increase and storage potential decrease (summarized by the 'high cost' and 'low potential' columns in Table 2 and Figure 1). The "optimistic storage" scenario combines the optimistic storage assumptions with the pessimistic hydrogen assumptions and vice versa in the "optimistic hydrogen" scenario. The efficiency, load factor, and lifetime remain constant in all scenarios. 


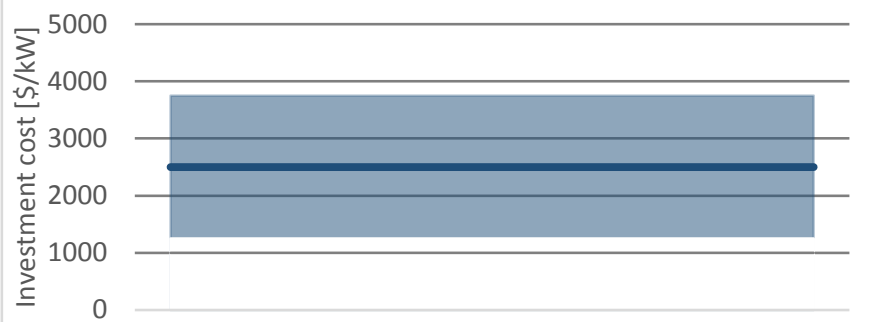

2010202020302040205020602070208020902100

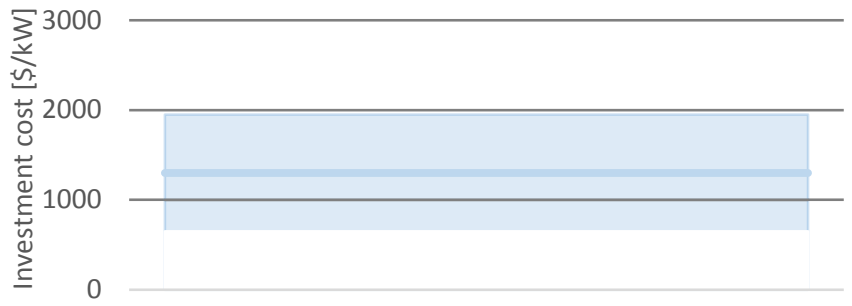

2010202020302040205020602070208020902100

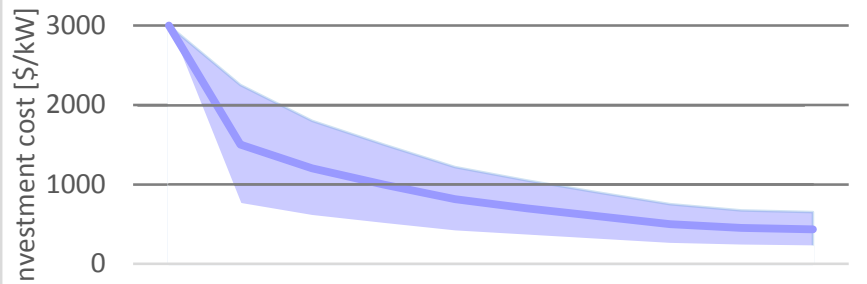

2010202020302040205020602070208020902100

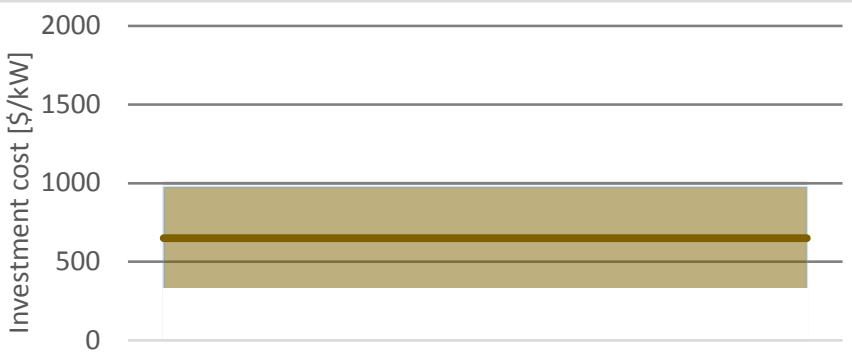

2010202020302040205020602070208020902100

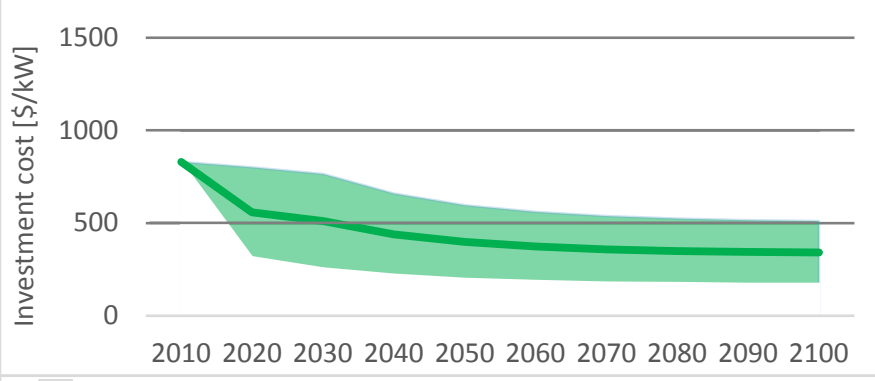

2010202020302040205020602070208020902100
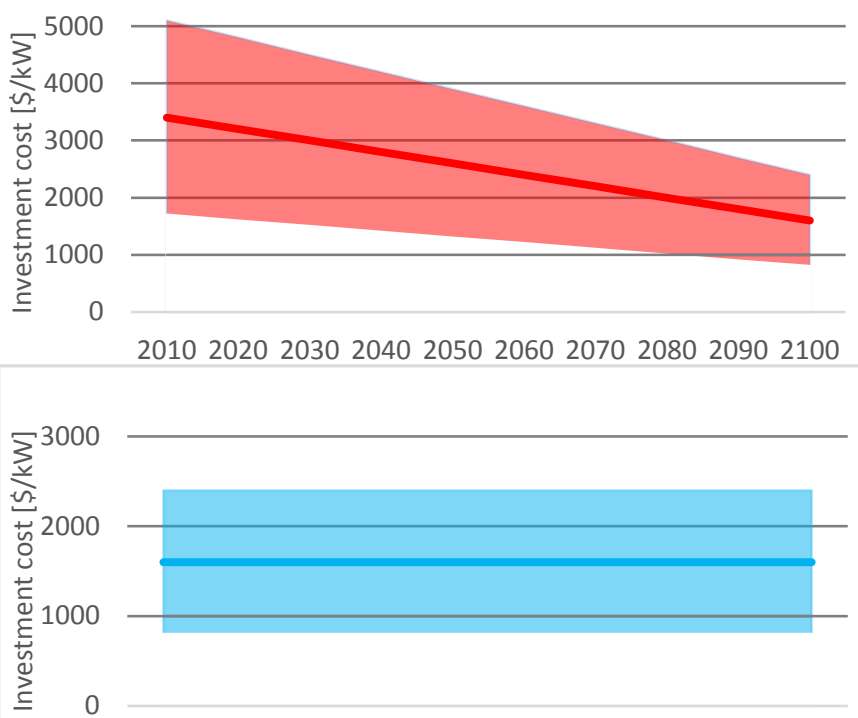

2010202020302040205020602070208020902100
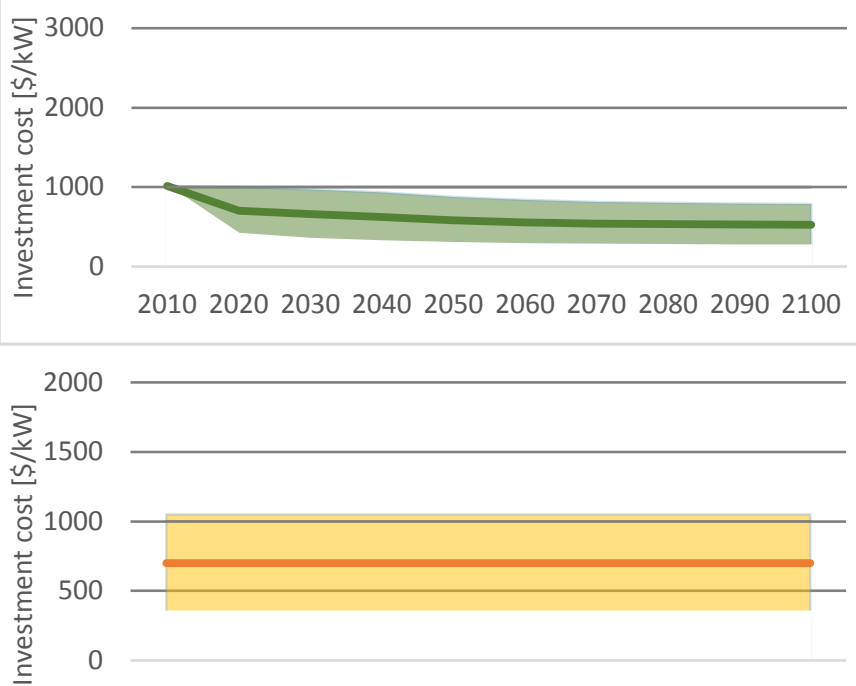

2010202020302040205020602070208020902100

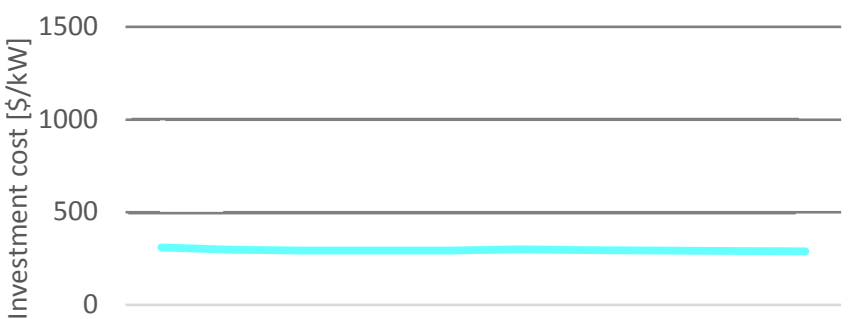

2010202020302040205020602070208020902100

$\longrightarrow$ PHS - 1 resevoir $\quad$ H2 Fuel cells

H2 Electrolysis H2 Combustion

Figure 1: Cost trajectories of storage and hydrogen technologies (with differing y-axes) over the analysis period under middle, optimistic and pessimistic sensitivities assumptions 


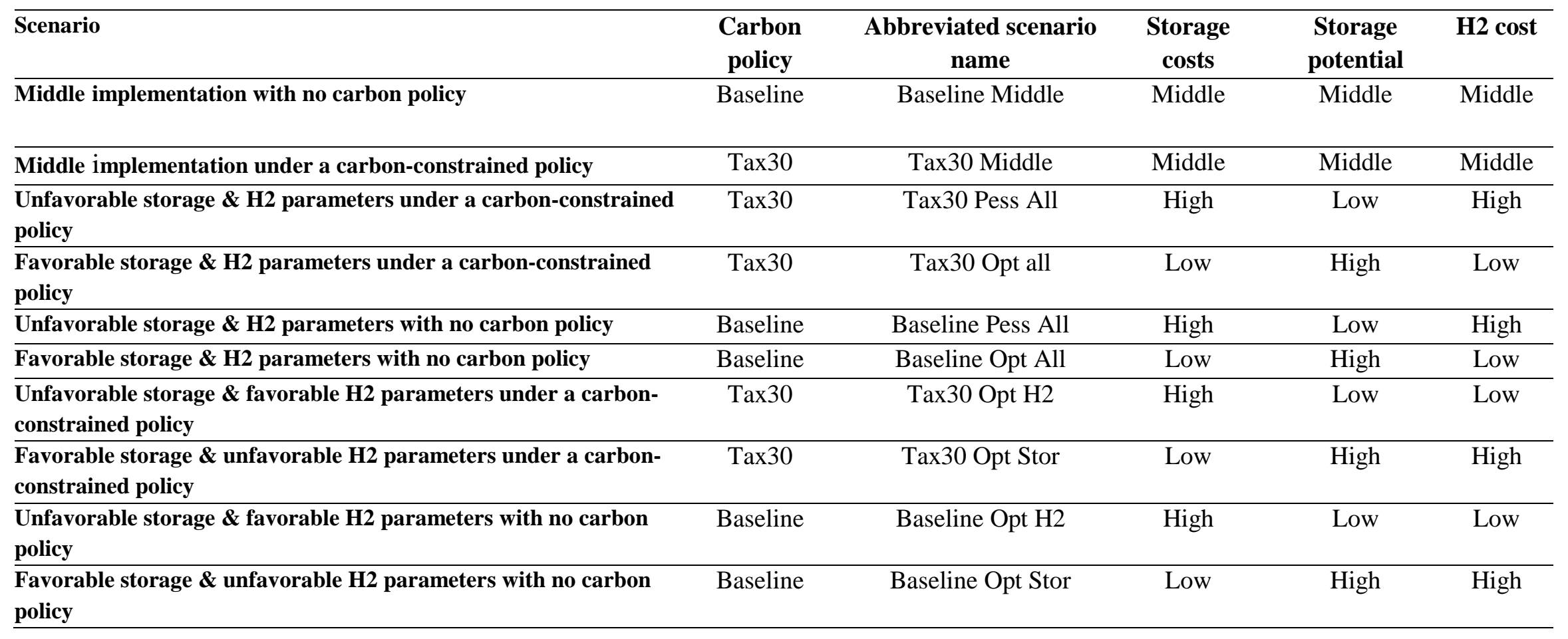

Table 1: The parameters corresponding to each of the tested scenarios, including carbon policy, storage implementation framework, costs, and potential 


\begin{tabular}{|c|c|c|c|c|c|c|c|c|c|c|}
\hline & $\begin{array}{c}\text { Low cost } \\
{[\$ / \mathbf{k W}]}\end{array}$ & $\begin{array}{c}\text { Middle } \\
\text { cost } \\
{[\$ / \mathbf{k W}]}\end{array}$ & $\begin{array}{c}\text { High cost } \\
{[\$ / \mathbf{k W}]}\end{array}$ & $\begin{array}{c}\text { Efficiency } \\
{[\%]}\end{array}$ & $\begin{array}{c}\text { Load } \\
\text { factor } \\
{[\%]}\end{array}$ & $\begin{array}{c}\text { Lifetime } \\
\text { [years] }\end{array}$ & $\begin{array}{c}\text { Low } \\
\text { potential }\end{array}$ & $\begin{array}{c}\text { Middle } \\
\text { potential }\end{array}$ & $\begin{array}{c}\text { High } \\
\text { potential }\end{array}$ & $\begin{array}{c}\mathrm{CO} 2 \\
\text { emissions }\end{array}$ \\
\hline $\begin{array}{l}\text { PHS: 2-existing } \\
\text { reservoir }\end{array}$ & 650 & 1300 & 1950 & $80 \%$ & $25 \%$ & 50 & $\begin{array}{c}2.5 \% \text { of } \\
\text { hydropower }\end{array}$ & $\begin{array}{c}5 \% \text { of } \\
\text { hydropower }\end{array}$ & $\begin{array}{c}7.5 \% \text { of } \\
\text { hydropower }\end{array}$ & Zero \\
\hline $\begin{array}{l}\text { PHS: 1-existing } \\
\text { reservoir }\end{array}$ & 800 & 1600 & 2400 & $80 \%$ & $25 \%$ & 50 & $\begin{array}{c}100 \% \text { of } \\
\text { hydropower }\end{array}$ & $\begin{array}{c}200 \% \text { of } \\
\text { hydropower }\end{array}$ & $\begin{array}{c}300 \% \text { of } \\
\text { hydropower }\end{array}$ & Zero \\
\hline PHS: Underground & 1250 & 2500 & 3750 & $80 \%$ & $25 \%$ & 50 & \multicolumn{3}{|c|}{ Unlimited } & Zero \\
\hline Compressor & & N/A & & N/A & $25 \%$ & 30 & \multicolumn{3}{|c|}{ Unlimited } & Zero \\
\hline Gas CT CAES & 325 & 650 & 975 & $51 \%$ & $43 \%$ & 30 & \multicolumn{3}{|c|}{ Unlimited } & \begin{tabular}{|c} 
As per gas \\
turbine
\end{tabular} \\
\hline H2 CT CAES & 350 & 700 & 1050 & $51 \%$ & $43 \%$ & 30 & \multicolumn{3}{|c|}{ Unlimited } & NOx \\
\hline H2 Fuel Cells & $3000-217$ & $3000-434$ & $3000-651$ & $47-58 \%$ & $35 \%$ & 20 & & Zero \\
\hline $\begin{array}{l}\text { Hydrogen } \\
\text { electrolysis }\end{array}$ & $830-171$ & $830-341$ & $830-512$ & $62-74 \%$ & $85 \%$ & 10 & \multicolumn{3}{|c|}{ Unlimited } & \\
\hline
\end{tabular}

Table 2: Techno-economic parameters associated with each scenario. Note that ranges within each column indicate the change in values between 2010 and 2100 . 


\section{$5 \quad$ Results and Discussion}

Ten scenarios are used to explore long-term energy transition pathways across two climate policies and a range of storage and hydrogen technology investment costs and potentials. The sensitivity of the electricity system to these assumptions are assessed by quantifying the implications for VRE deployment (Section 5.1), the electricity generation portfolio (Sections 5.2), flexible generation and firm capacity (Section 5.3), VRE curtailment (Section 5.4) and climate change mitigation costs (Section 5.5).

\subsection{VRE Penetration}

In the Baseline scenarios, the hydrogen-storage sensitivities have a significant impact on VRE penetration. Optimistic hydrogen and storage assumptions ('Baseline Opt All') induce a 2\%point increase (reaching 57\% penetration by 2100) relative to 'Baseline Middle', while pessimistic assumptions ('Baseline Pess All') induce a 14\%-point decrease (reaching 41\% VRE penetration by 2100) (refer to the brown lines in Figure 2). The primary reason for the large reduction in VRE share with pessimistic assumptions is the fact that only one technology, hydrogen electrolysis with seasonal storage, can mitigate seasonal curtailment in the model. Thus, when hydrogen electrolysis is expensive, VRE deployment is reduced to levels at which seasonal curtailment is negligible. For this reason, the two scenarios with pessimistic hydrogen assumptions ('Baseline Pess All' and 'Baseline Opt Stor') exhibit the two lowest VRE deployment rates. These results suggest that enhanced $R \& D$ investment that focuses on reducing the costs of technologies which mitigate seasonal-scale VRE variability will be important for enabling large-scale VRE deployment in electricity systems without climate policy.

In contrast, the global VRE penetration reaches $83 \%$ by 2100 in the 'Tax30 Middle' scenario and varies by only three percentage points across the full range of optimistic and pessimistic technology assumptions (refer to the green lines in Figure 2). The insensitivity of VRE deployment to hydrogen and storage costs in the presence of climate policy results from the limited potential of other low-carbon alternatives in MESSAGE. For example, nuclear is expensive and incompatible with moderate VRE deployment rates due to its inflexibility, while hydro and geothermal deployment potentials are limited. Solar thermal is also expensive but is deployed to provide system flexibility when storage and hydrogen are expensive (discussed 
later). Despite a limited global impact, storage and hydrogen cost assumptions have a more significant impact in specific regions, such as the Pacific OECD and North America. Given the limited impact of pessimistic storage and hydrogen assumptions on global VRE deployment in the Tax30 scenarios, we must ask how the system manages to integrate large shares of VRE in the face of high costs. For example, does it deploy storage and hydrogen technologies despite the high costs or does the system adapt in other ways? The next sections seek to answer this question.

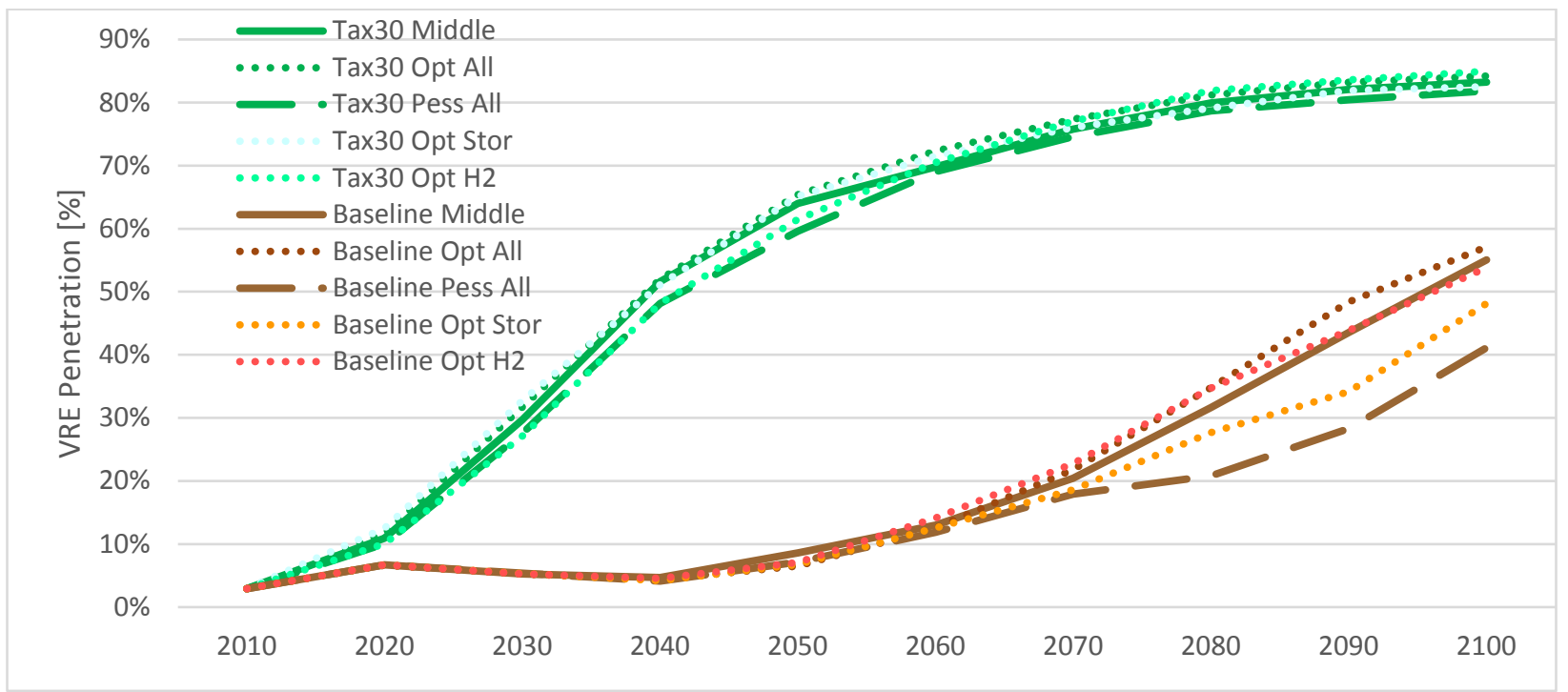

Figure 2: Global VRE penetration in each scenario

\subsection{Electricity Portfolio}

In both the Baseline and Tax30 scenarios, the electricity generation portfolio changes in response to different hydrogen and storage techno-economic assumptions (Figure 3). Differences in generation portfolios provide insight into how systems adapt to large-scale VRE deployment and the implications for the greenhouse gas (GHG) intensity of the power sector.

In the Baseline scenarios, storage technologies contribute between $0 \%$ and $5 \%$ of generation by 2100 in the 'Baseline Pess All' and 'Baseline Opt All' scenarios, respectively. Gas CAES dominates storage deployment since it is the lowest cost option when there is no carbon tax (Figure 4). Hydrogen technologies generate 2\%-12\% of generation by 2100 in the 'Baseline Opt Stor' and 'Baseline Opt H2' scenarios, respectively. Under optimistic pricing assumptions, utility-scale fuel cells are cheaper than gas or hydrogen combustion turbines and thus provide 
cost-competitive flexible generation. However, in these scenarios, the hydrogen is largely produced from coal and thus is not low-carbon.

Moreover, the reduced VRE generation resulting from pessimistic storage and hydrogen assumptions is substituted by coal- and gas-based generation. In particular, the share of coalbased generation increases seven-fold when pessimistic rather than optimistic storage and hydrogen characteristics are assumed ('Baseline Pess All’ versus ‘Baseline Opt All’). This finding highlights the sustained importance of fossil resources and the associated climate risks when hydrogen and storage technological learning is slow. Thus, in the absence of climate policy, investment in storage and hydrogen R\&D will be critical for promoting VRE deployment and mitigating climate change. Reducing the costs of hydrogen electrolyzers and fuel cells have a larger impact on VRE deployment than reducing electricity storage costs.

Cost sensitivities also impact the deployment of electricity storage technologies in the Tax30 scenarios. Whereas there is no deployment of storage technologies in 2100 when storage assumptions are pessimistic ('Tax30 Pess All’ and 'Tax30 Opt H2'), storage technologies provide 6\% and 8\% of total electricity generation in 'Tax30 Opt All' and 'Tax30 Opt Stor', respectively. While gas CAES dominates storage deployment in the Baseline scenarios, the carbon price in the Tax30 scenarios discourages gas CAES due to the emission from gas combustion. Instead, PHS dominates storage deployment with hydrogen CAES also playing a small role in 'Tax30 Opt Stor'. Batteries are not competitive with the other storage technologies for bulk energy storage in these scenarios.

The significant increase in storage deployment under optimistic cost assumptions is balanced by a decrease in hydrogen deployment, suggesting a substitutive relationship between hydrogen and storage. Interestingly, when both hydrogen and storage assumptions are optimistic ('Tax30 Opt All'), more electricity is generated from storage technologies than hydrogen technologies. However, when assumptions are pessimistic for both technologies ('Tax30 Pess All'), there is no deployment of electricity storage, suggesting that storage deployment is very sensitive to cost. Moreover, the total generation from both hydrogen and storage technologies declines substantially to $17 \mathrm{EJ}$ in 2100 in 'Tax30 Pess All'. Unlike the Baseline scenarios, high VRE shares are sustained in the Tax30 scenarios even when pessimistic hydrogen and storage assumptions are imposed, which raises the question as to how large shares of VRE are integrated 
when hydrogen and storage deployment is reduced. Figures 3 and 4 suggest that concentrating solar power generators with thermal storage and hydrogen combustion turbines provide the necessary system flexibility and firm capacity when storage and hydrogen assumptions are less than optimistic.

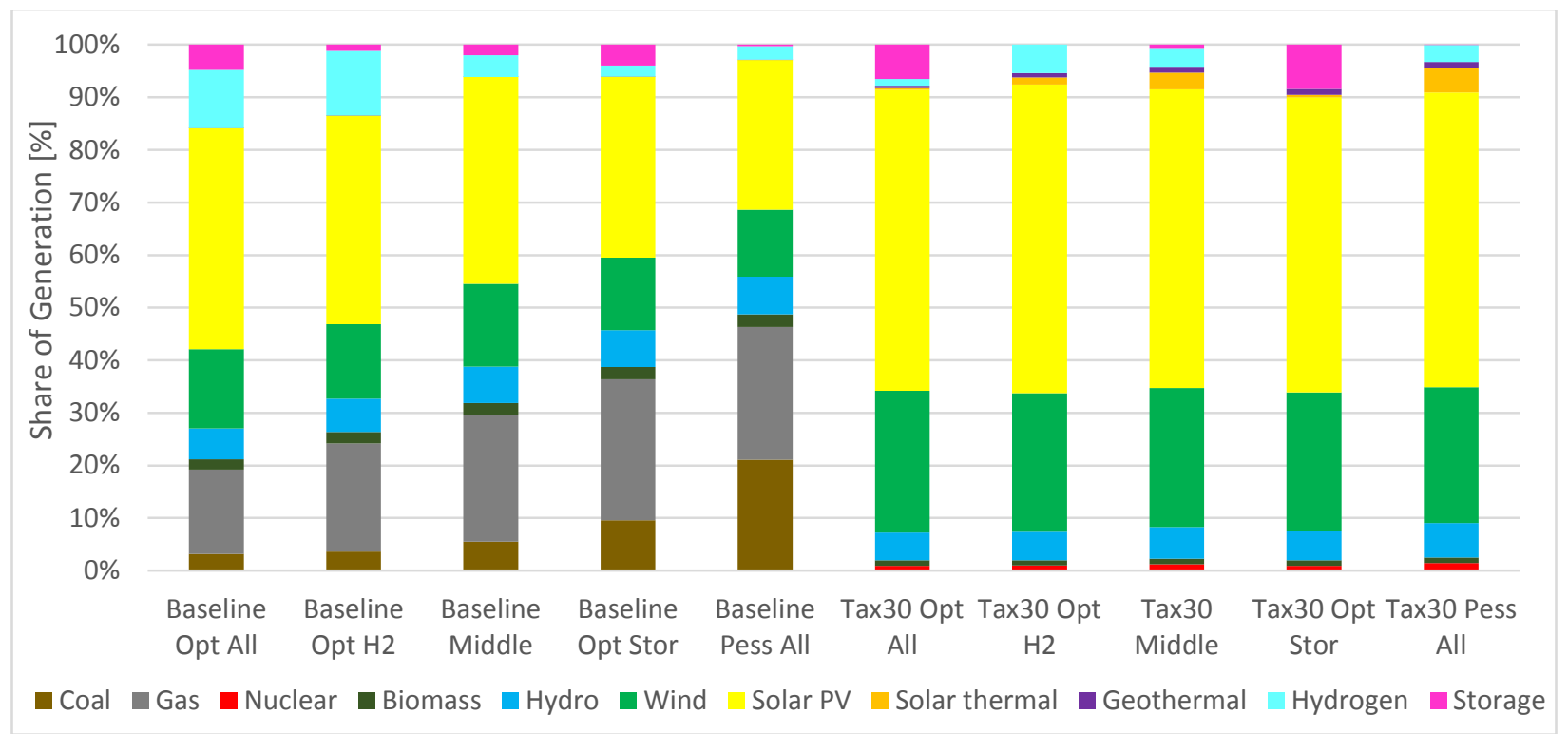

Figure 3:Share of electricity generation by technology in each scenario in 2100

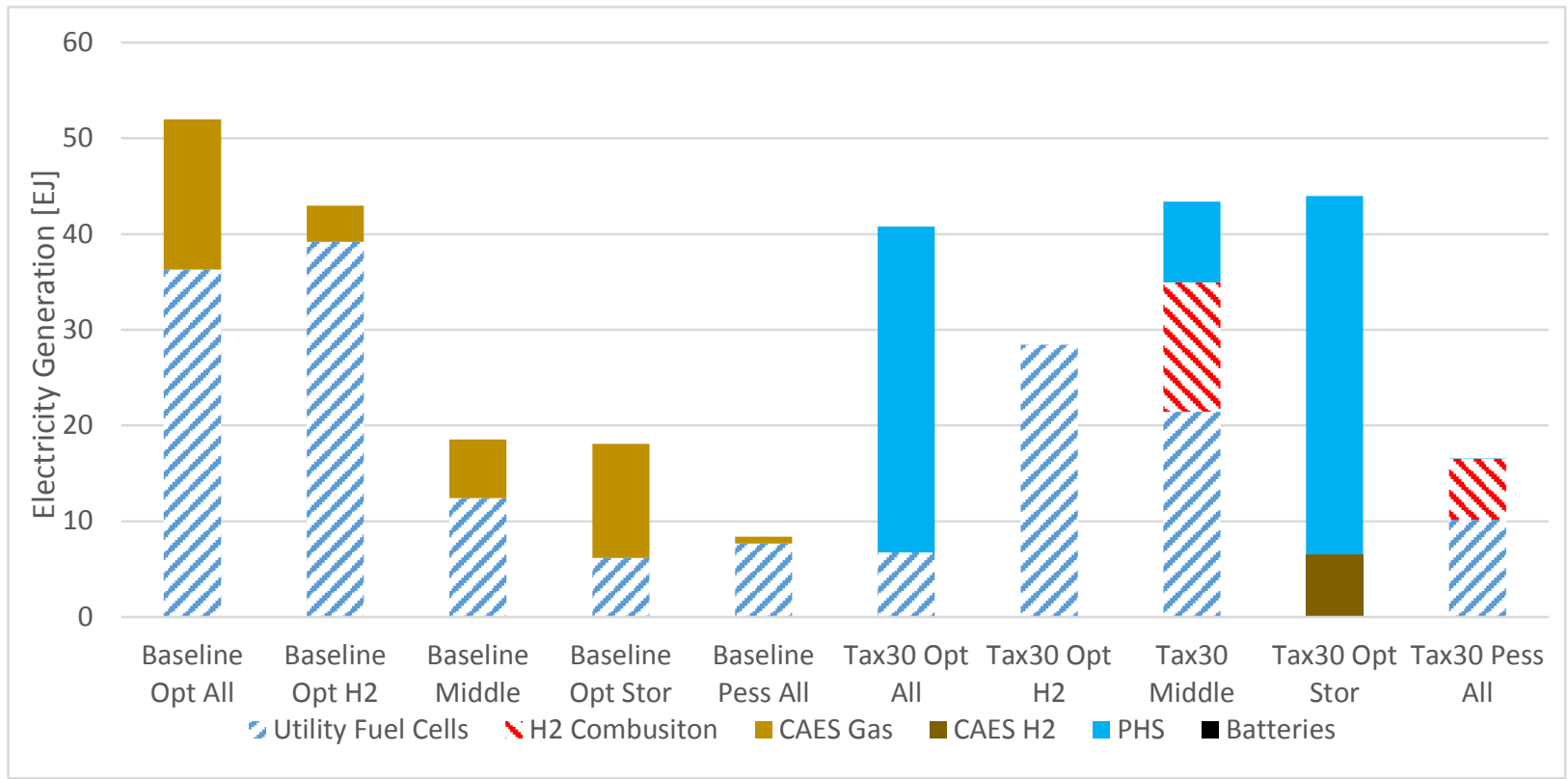

Figure 4: Global storage and hydrogen generation in each scenario in 2100

Despite the absence of climate policy, we find that hydrogen-based generation is larger in the Baseline scenarios than the Tax30 scenarios in 2100 when hydrogen assumptions are optimistic 
(Opt All and Opt H2). As utility-scale fuel cells become competitive with gas combustion turbines, they are deployed to meet the system flexibility requirements, which are large even at the VRE shares deployed in the Baseline scenarios ( 40-60\% of non-VRE generation must be flexible). Furthermore, hydrogen is cheaper in the Baseline scenarios since it is produced using coal rather than electrolysis. In contrast, hydrogen-based generation is smaller in the Tax30 scenarios because the amount of flexible generation required declines as non-VRE occupies a smaller share of total generation. This finding suggests that larger VRE shares will not necessarily require more hydrogen-based generation.

When storage assumptions are optimistic (Opt All and Opt Stor), we find larger deployment of storage technologies in the Tax30 scenarios than the Baseline scenarios. At the large VRE shares found in the Tax30 scenarios, significant curtailment must be managed by hydrogen electrolyzers and/or electricity storage technologies. When storage costs are optimistic, substantial storage is deployed to mitigate curtailment and, given that this technology also provides flexible generation, this deployment leads to large storage-based generation. In contrast, the hydrogen technologies used to mitigate curtailment (electrolyzers) and to provide flexible generation and firm capacity (fuel cells and combustion turbines) are separate. Thus, although electrolyzers are deployed to handle curtailment in the Tax30 scenarios, the hydrogen is not necessarily used to generate electricity. Overall, curtailment mitigation seems to be the primary driver of the deployment of hydrogen and storage technologies in the Tax30 scenarios, whereas the need for flexible generation is the main driver in the Baseline scenarios.

\subsection{Flexible Generation and Firm Capacity}

As VRE deployment increases, the flexible share of total generation decreases as the non-VRE share decreases, but the share of non-VRE generation that must be flexible increases and reaches nearly $100 \%$ at the VRE shares in the Tax30 scenarios. The extent to which storage technologies contribute to system flexibility depends on climate policy and their costs relative to competing technologies that provide similar VRE integration services (e.g., curtailment mitigation and system flexibility). Storage technologies only contribute significantly to system flexibility when techno-economic assumptions are optimistic and appear especially useful for integrating the large shares of VRE deployed in the Tax30 scenarios since they can provide curtailment mitigation, system flexibility, and firm capacity (Figure 5). However, when storage costs are not 
optimistic, hydrogen technologies provide significant flexible generation, especially when techno-economic assumptions are only optimistic for hydrogen technologies (Opt H2).

In the Baseline scenarios, flexibility is mostly provided in 2100 by gas, hydrogen fuel cells, and hydro, but note that the gas share increases as hydrogen assumptions become less optimistic. Gas CAES also plays a role in the Baseline scenarios but is phased out when carbon taxes are implemented in the Tax30 scenarios. When a climate policy is implemented, flexibility in the decarbonized electricity system is provided primarily by hydro, CSP, and a mix of storage and hydrogen technologies that depends on their relative costs. By 2100, the storage-hydrogen contribution to system flexibility reaches 67\% in 'Tax30 Opt All', but only 31\% in 'Tax30 Pess All'. When both hydrogen and storage technologies have middle to high costs, CSP with thermal storage provides more than $15 \%$ of flexible generation, highlighting its potential role as a flexible and low-carbon option.

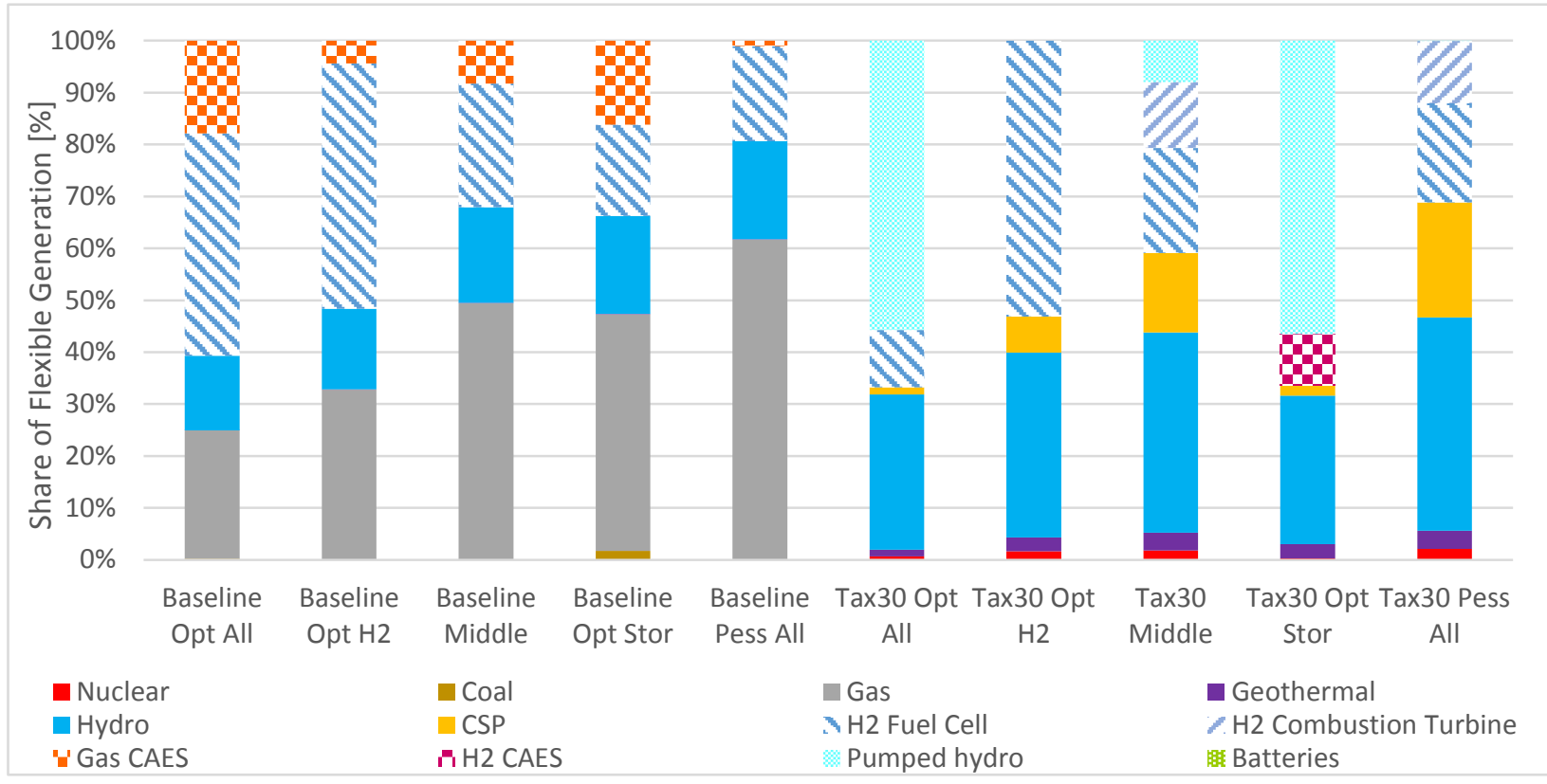

Figure 5: The share of flexible generation by technology in each scenario in 2100

The electricity system must also maintain sufficient firm capacity to meet peak load and contingencies. However, the fraction of VRE that is considered firm (i.e., the capacity value) declines with increasing deployment. As a result, the ratio of total installed capacity to annual average load increases with VRE deployment. For example, the ratio is roughly two at near-zero VRE penetration, but more than five at VRE shares consistent with the Tax30 scenarios. In the 
Baseline scenarios, gas technologies dominate firm capacity provision unless hydrogen assumptions are optimistic (Figure 6). Under optimistic hydrogen assumptions ('Baseline Opt All' and 'Baseline Opt H2'), utility-scale fuel cells are competitive with gas and provide nearly $60 \%$ of the reserve capacity. When only storage assumptions are optimistic ('Baseline Opt Stor'), gas CAES provides about $30 \%$ of firm capacity.

In the Tax30 scenarios, hydrogen combustion turbines replace gas combustion turbines as the primary supplier of firm capacity when neither hydrogen nor storage assumptions are optimistic ('Tax30 Middle' and 'Tax30 Pess All'). Utility-scale fuel cells provide the most firm capacity when hydrogen assumptions are optimistic ('Tax30 Opt All' and 'Tax30 Opt H2'), while hydrogen CAES and pumped hydro are dominant when only storage assumptions are optimistic ('Tax30 Opt Stor'). Hydrogen combustion turbines and fuel cells are preferred for firm capacity provision because investment costs are relatively low and they can be operated at small load factors, which minimizes their operating costs. On the other hand, MESSAGE does not build storage technologies for firm capacity alone.

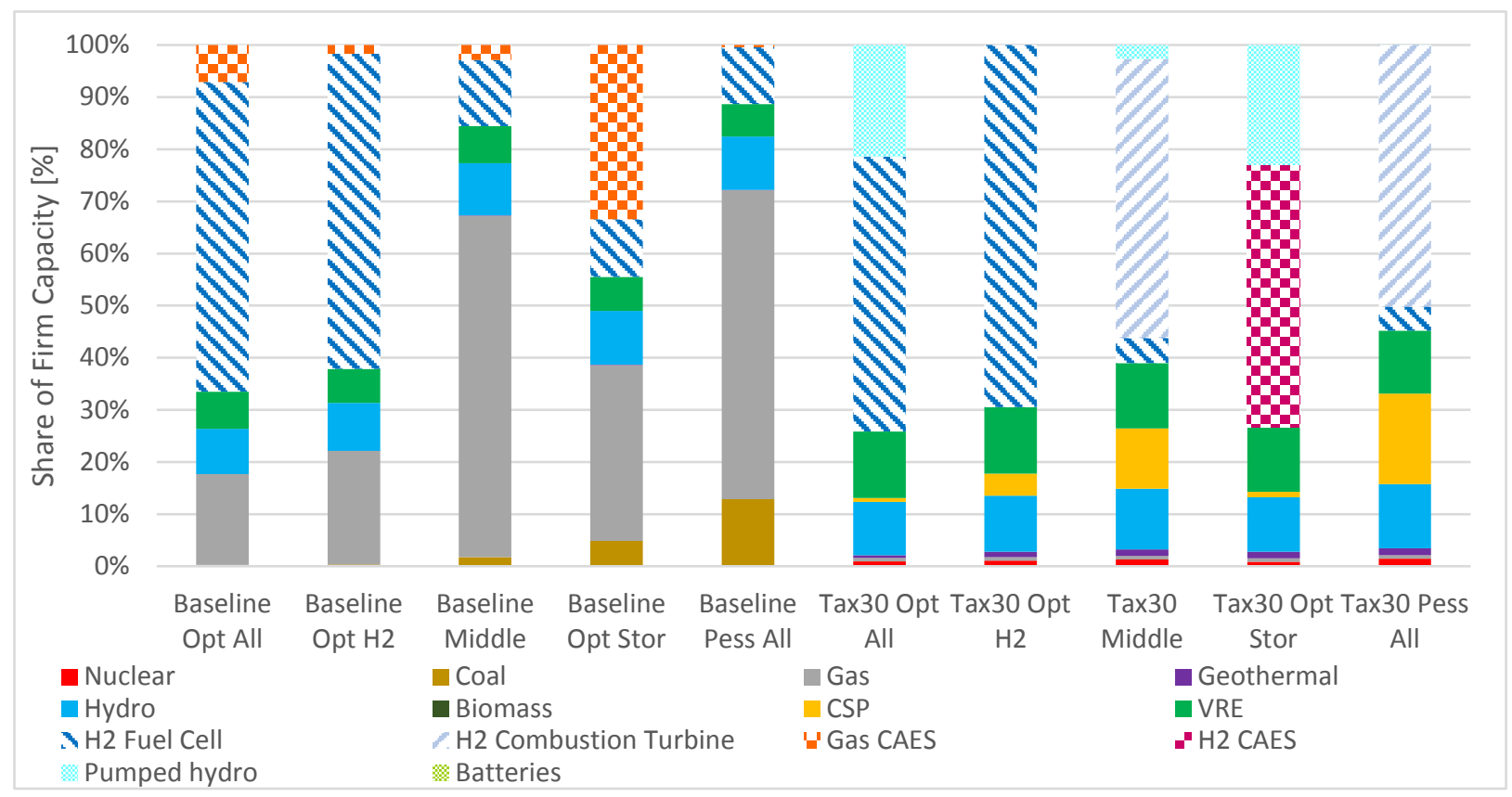

Figure 6: Share of firm capacity in each scenario in 2100

\subsection{Curtailment Mitigation}

Regardless of the cost sensitivities and VRE shares explored in this analysis, it is less expensive to mitigate VRE curtailment than to curtail electricity. In the model, surplus electricity is used to 
produce hydrogen or to energize storage assets and the energy absorbed by these technologies either matches or exceeds the theoretical curtailment rates, resulting in zero or near-zero actual curtailment (Figure 7). Theoretical curtailment is very low in the Baseline scenarios because the shares of VRE remain small (Figure 7). When both electrolysis and storage costs are large ('Baseline Pess All'), the VRE share is restricted to its smallest value of 41\%, which is a level at which curtailment is negligible. Moreover, despite optimistic storage costs, the pessimistic electrolysis costs found in 'Baseline Opt Stor' result in a reduced VRE share because hydrogen electrolysis with hydrogen storage is the only technology in MESSAGE for mitigating seasonal curtailment. Thus, when the technologies for mitigating curtailment are expensive, the VRE share is suppressed rather than allowing curtailment.

Across the Tax30 scenarios, theoretical total curtailment remains similar since the VRE share doesn't vary much among these scenarios. However, there are some variations that result from differences in regional VRE deployment. For example, optimistic electrolysis costs ('Tax30 Opt H2') enable VRE to be deployed in regions with more curtailment while pessimistic electrolysis costs ('Tax30 Pess All' and 'Tax30 Opt Stor') shifts VRE deployment to regions with less curtailment. Seasonal hydrogen storage is the only technology that can mitigate seasonal curtailment and, consequently, the electricity used by this technology matches the theoretical seasonal curtailment exactly. However, short-term curtailment can be mitigated by several technologies, including hydrogen electrolyzers and the various storage technologies. The relative contributions of hydrogen electrolysis and electricity storage in mitigating short-term curtailment depend on their respective cost assumptions. In 2100, storage only contributes to curtailment mitigation under optimistic assumptions ('Tax30 Opt All’ and 'Tax30 Opt Stor') and is displaced by electrolysis under middle or pessimistic assumptions ('Tax30 Middle’, 'Tax30 Opt H2', and 'Tax30 Pess All'). Note that hydrogen electrolysis is deployed for curtailment mitigation even when it is not competitive with storage ('Tax30 Opt Stor') because it is a low-carbon method for producing hydrogen which can then be used to decarbonize energy demands that cannot be easily electrified (e.g., industrial heat and international shipping). Across all Tax30 scenarios, the electricity used by hydrogen and storage technologies exceeds the amount required to mitigate curtailment, which suggests that these technologies are also being used to convert inflexible baseload generation into flexible generation to meet system flexibility requirements. 


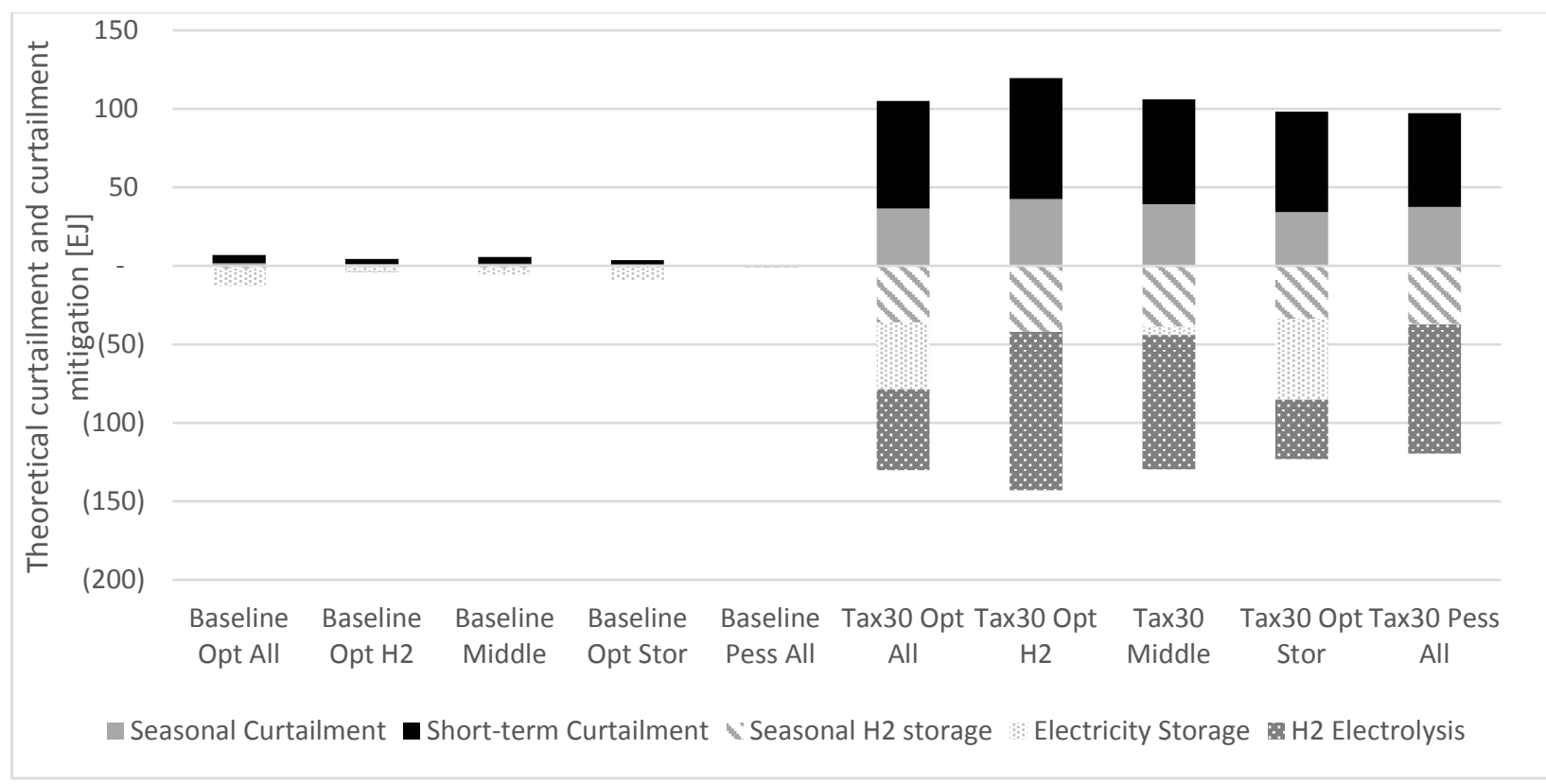

Figure 7: Sources of VRE curtailment (short-term and seasonal) and curtailment mitigation (seasonal hydrogen storage, electricity storage, or electrolysis) globally in 2100 in each scenario

\subsection{Mitigation Costs}

The cumulative GDP loss in each scenario is calculated by summing the net present value across all time periods of the difference in GDP between each scenario and 'Baseline Middle'. All scenarios with climate policy ('Tax30’) incur approximately a 24 trillion USD2005 GDP loss over the 2010-2100 timeframe, as compared to 'Baseline Middle’, which has no climate policy. Relative to the large economic impact of climate policy, different storage and hydrogen assumptions have a smaller, though still significant impact. Optimistic assumptions regarding either hydrogen or storage costs ('Tax30 Opt H2’ or 'Tax30 Opt Stor’) achieve similar savings of $0.7 \%$ relative to 'Tax30 Middle'. When both hydrogen and storage assumptions are optimistic ('Tax30 Opt All'), the savings increase to 1.7\%, while pessimistic assumptions ('Tax30 Pess All') result in a relative loss of $0.8 \%$. Thus, overall, there is a $2.5 \%$ difference in the cumulative GDP loss between 'Tax30 Opt All' and 'Tax30 Pess All', suggesting that investment in storage and hydrogen R\&D could yield economic benefits in a world with climate policy.

In contrast, different storage and hydrogen techno-economic assumptions have little impact on GDP in the scenarios with no climate policy ('Baseline'), yielding at most a cumulative GDP gain of 100 billion USD2005 when assumptions for both technologies are optimistic ('Baseline 
Opt All'). Thus, even though Section 5.1 suggests that investment into storage and hydrogen R\&D is important for driving VRE deployment in the absence of climate policy, limiting R\&D investments will have a small impact on the global economy.

\section{$6 \quad$ Limitations}

There are numerous limitations associated with the energy storage technology profiles that have been included in the MESSAGE model. First, the evolution of each technology over the coming century is laden with uncertainty that could materially impact the techno-economic assumptions and results, particularly in the later portion of the analysis period. In particular, the rapid evolution of battery technologies is difficult to forecast accurately. Further, each technology's techno-economic characteristics will vary depending on local site characteristics and regulatory frameworks, which could also materially impact the storage market’s development.

Moreover, this analysis only considers a subset of currently or potentially available storage technologies while omitting technologies like flywheels and supercapacitors. In addition, MESSAGE does not include several possible hydrogen use pathways, such as methanation and transport fuels, which would not contribute to VRE integration, but may incentivize hydrogen production via electrolysis and thus impact the electricity sector. Further, biological hydrogen production methods including biohydrogen fermentation [77], lignocellulose hydrogen conversion [78], and microbial electrohydrogenesis [79] have not been considered due to their technological immaturity [62]. Finally, there are limitations with the MESSAGE representation of storage technologies more generally, including the annual timestep, regional spatial resolution, and simplified representation of storage services. Thus, the results presented in this paper should be treated as high-level insights, rather than forecasts.

\section{Conclusions}

The following conclusions highlight the key implications of uncertainty in future electricity storage and hydrogen technology costs for VRE deployment and the electricity portfolio more broadly, focusing on the most important policy insights from the perspective of climate change mitigation. 
1) In the absence of carbon policy, hydrogen and storage technology $R \& D$ that drive cost reductions will be required to facilitate VRE deployment and mitigate coal generation.

Storage and hydrogen technology sensitivities have a limited impact on VRE deployment in the Tax30 scenarios where VRE shares range from $82 \%$ to $85 \%$ in 2100 across the different storage and hydrogen assumptions. In contrast, VRE penetrations range significantly from $41 \%$ to $57 \%$ in 2100 across the Baseline scenarios. Coal is the primary substitute for the lost VRE generation as storage and hydrogen assumptions become less optimistic. Consequently, in the absence of climate policy, storage and hydrogen R\&D investments, which focus on lowering technology costs, will be critical for promoting VRE deployment and mitigating coal generation. Investments to reduce the cost of power-to-gas (electrolysis) appears particularly important for facilitating VRE shares above $40 \%$ where seasonal curtailment becomes an issue.

2) Large-scale deployment of electricity storage technologies only occurs when technoeconomic assumptions are optimistic.

Electricity storage technologies appear particularly sensitive to cost given that almost no storage is deployed when costs are pessimistic and very little is deployed under medium costs, especially with climate policy. However, in scenarios with optimistic costs and climate policy, storage appears to be the preferred VRE integration technology, even when hydrogen costs are also optimistic ('Tax30 Opt All'). Although gas CAES is the preferred storage technology in the scenarios without climate policy, the implementation of a carbon tax shifts electricity storage to technologies with low GHG emissions, including pumped hydro and hydrogen CAES. Storage technologies are valuable because they not only mitigate curtailment but also provide flexible generation and firm capacity.

3) Power-to-gas (electrolysis) is an important technology for mitigating climate change as it can contribute to the decarbonization of many sectors.

As expected, when hydrogen electrolysis and fuel cell costs are optimistic, these technologies are widely used to integrate VRE. Yet, when costs are less than optimistic, we see a decrease in the contribution of fuel cells to flexible generation and firm capacity and no deployment of fuel cells in the scenario where storage costs are optimistic while hydrogen costs are pessimistic ('Tax30 Opt Stor'). However, in the case of electrolyzers, even when the costs are pessimistic, they are 
deployed widely for mitigating both seasonal and short-term curtailment. They are deployed for seasonal curtailment because electrolysis with long-term hydrogen storage is the only technology available in the model for addressing this curtailment. But short-term curtailment could be addressed solely by electricity storage technologies, and yet electrolyzers are still deployed, even when hydrogen is not used for electricity generation ('Tax30 Opt Stor'). This finding results from the fact that hydrogen can be used to decarbonize energy demands that are not easily electrified, such as industrial processes requiring heat and long-distance shipping. Thus, electrolysis is a means for producing low-GHG hydrogen, which can then be used to decarbonize other sectors to achieve climate change mitigation targets. Note that electrolysis would likely increase further if the potentially large market for hydrogen in the transport sector was included in the model.

4) Large VRE shares can still be supported in carbon-constrained futures with pessimistic storage and hydrogen technology costs.

The contribution of storage and hydrogen technologies to VRE integration is highly sensitive to their respective costs. In the Baseline case, hydrogen fuel cells contribute a substantial share of flexible generation and firm capacity as their costs become competitive with gas combustion turbines under optimistic hydrogen assumptions. Similarly, gas CAES is deployed for VRE integration when storage assumptions are optimistic. We find similar outcomes in the Tax30 scenarios where PHS and hydrogen CAES are the dominant storage technologies while fuel cells are deployed for both firm capacity and flexibility under favorable cost assumptions. However, in Tax30 scenarios where both hydrogen and storage cost assumptions are middle or pessimistic ('Tax30 Middle' and 'Tax30 Pess All’), large VRE shares are sustained despite limited contributions of storage and fuel cell technologies to system flexibility and firm capacity. In these scenarios, system flexibility and firm capacity are provided by concentrating solar power with thermal storage and hydrogen combustion turbines, which appear to be important lowcarbon flexible technologies for integrating VRE in the absence of low-cost storage and hydrogen technologies.

5) $R \& D$ investments that lower the costs of storage and hydrogen technologies will reduce the cost of the low-carbon energy transition required to mitigate climate change. 
In the Tax30 scenarios, we find that optimistic assumptions about either hydrogen or storage technologies ('Tax30 Opt H2' or 'Tax30 Opt Stor') can reduce the global cumulative GDP loss by about $0.7 \%$ relative to 'Tax30 Middle', while it is decreased by about $1.7 \%$ when assumptions are optimistic for both technologies ('Tax30 Opt All'). Pessimistic assumptions for both technologies ('Tax30 Pess All') increase the loss by $0.8 \%$, which indicates that R\&D investments that drive down the costs of both technologies could reduce the GDP loss by $2.5 \%$ relative to a scenario where costs remain high as in the pessimistic scenario. Thus, although cost sensitivities seem to have little impact on VRE deployment in climate change mitigation scenarios, they could have a large impact on the cost of the required energy transition. In contrast, a failure to make R\&D investments is not expected to have a large impact on the economy when climate policy is not implemented ('Baseline') but does impact VRE deployment and coal-based generation, which suggests that they are important for reducing GHG emissions in the absence of climate policy. 


\section{Acknowledgements}

We gratefully acknowledge the Young Scientist Summer Program at the International Institute for Applied Systems Analysis, the Natural Sciences and Engineering Research Council of Canada (NSERC), and the European Union's Seventh Programme FP7/2007-2013 under grant agreement $n^{\circ} 308329$ (ADVANCE) for their funding of this work. 


\section{References}

[1] de Boer HS, Grond L, Moll H, Benders R. The application of power-to-gas, pumped hydro storage and compressed air energy storage in an electricity system at different wind power penetration levels. Energy 2014;v 72:360-70. doi:10.1016/j.energy.2014.05.047.

[2] OECD/IEA. IEA Statistics: Renewables Information 2012. vol. 5. Paris, France: International Energy Agency; 2012.

[3] Jacobson MZ, Delucchi MA. Providing all global energy with wind, water, and solar power, Part I: Technologies, energy resources, quantities and areas of infrastructure, and materials. Energy Policy 2011;39:1154-69. doi:10.1016/j.enpol.2010.11.040.

[4] Ren21. Renewables 2014 Global Status Report. 2014.

[5] Luderer G, Pietzcker RC, Carrara S, de Boer HS, Fujimori S, Johnson N, et al. Assessment of wind and solar power in global low-carbon energy scenarios: An introduction. Energy Econ 2017;64:542-51. doi:10.1016/j.eneco.2017.03.027.

[6] Hirth L, Ueckerdt F, Edenhofer O. Integration costs revisited - An economic framework for wind and solar variability. Renew Energy 2015;74:925-39. doi:10.1016/j.renene.2014.08.065.

[7] Denholm P, Ela E, Kirby B, Milligan M. The role of energy storage with renewable electricity generation 2010 .

[8] Zakeri B, Rinne S, Syri S. Wind integration into energy systems with a high share of nuclear power-what are the compromises? Energies 2015;8:2493-527. doi:10.3390/en8042493.

[9] Lund H, Østergaard PA, Connolly D, Ridjan I, Mathiesen BV, Hvelplund F, et al. Energy Storage and Smart Energy Systems. Int J Sustain Energy Plan Manag 2016;11:3-14. doi:10.5278/ijsepm.2016.11.2.

[10] Berrada A, Loudiyi K, Zorkani I. Valuation of energy storage in energy and regulation markets. Energy 2016;115:1109-18. doi:10.1016/j.energy.2016.09.093. 
[11] Liu Y, Woo CK. California’s renewable generation and pumped hydro storage's profitability. Electr J 2017;30:15-22. doi:10.1016/j.tej.2017.02.009.

[12] Li N, Hedman KW. Economic Assessment of Energy Storage in Systems with High Levels of Renewable Resources. IEEE Trans Sustain Energy 2015;6:1103-11. doi:10.1109/TSTE.2014.2329881.

[13] de Sisternes FJ, Jenkins JD, Botterud A. The value of energy storage in decarbonizing the electricity sector. Appl Energy 2016;175:368-79. doi:10.1016/j.apenergy.2016.05.014.

[14] Forrest KE, Tarroja B, Zhang L, Shaffer B, Samuelsen S. Charging a renewable future: The impact of electric vehicle charging intelligence on energy storage requirements to meet renewable portfolio standards. J Power Sources 2016;336:63-74. doi:10.1016/j.jpowsour.2016.10.048.

[15] Cebulla F, Fichter T. Merit order or unit-commitment: How does thermal power plant modeling affect storage demand in energy system models? Renew Energy 2017;105:11732. doi:10.1016/j.renene.2016.12.043.

[16] Krey V. Global energy-climate scenarios and models: a review. Wiley Interdiscip Rev Energy Environ 2014;3:363-83. doi:10.1002/wene.98.

[17] Pietzcker RC, Ueckerdt F, Carrara S, de Boer HS, Després J, Fujimori S, et al. System integration of wind and solar power in integrated assessment models: A cross-model evaluation of new approaches. Energy Econ 2017;64:583-99. doi:10.1016/j.eneco.2016.11.018.

[18] Messner S, Strubegger M. User’s Guide for MESSAGE III. Laxenburg, Austria: 1995.

[19] Riahi K, Dentener F, Gielen D, Grubler A, Jewell J, Klimont Z, et al. Chapter 17 - Energy Pathways for Sustainable Development. Glob. Energy Assess. - Towar. a Sustain. Futur., Cambridge University Press, Cambridge, UK and New York, NY, USA and the International Institute for Applied Systems Analysis, Laxenburg, Austria: 2012, p. 1203306.

[20] Sullivan P, Krey V, Riahi K. Impacts of considering electric sector variability and 
reliability in the MESSAGE model. Energy Strateg Rev 2013;1:157-63. doi:10.1016/j.esr.2013.01.001.

[21] Johnson N, Strubegger M, McPherson M, Parkinson SC, Krey V, Sullivan P. A reducedform approach for representing the impacts of wind and solar PV deployment on the structure and operation of the electricity system. Energy Econ 2017;64. doi:10.1016/j.eneco.2016.07.010.

[22] International Energy Agency. Technology Roadmap Energy Storage. 2014.

[23] Akinyele DO, Rayudu RK. Review of energy storage technologies for sustainable power networks. Sustain Energy Technol Assessments 2014;8:74-91. doi:10.1016/j.seta.2014.07.004.

[24] Luo X, Wang J, Dooner M, Clarke J. Overview of current development in electrical energy storage technologies and the application potential in power system operation. Appl Energy 2014;137:511-36. doi:10.1016/j.apenergy.2014.09.081.

[25] Aneke M, Wang M. Energy storage technologies and real life applications - A state of the art review. Appl Energy 2016;179:350-77. doi:10.1016/j.apenergy.2016.06.097.

[26] Ueckerdt F, Pietzcker R, Scholz Y, Stetter D, Giannousakis A, Luderer G. Decarbonizing global power supply under region-specific consideration of challenges and options of integrating variable renewables in the REMIND model. Energy Econ 2016. doi:doi:10.1016/j.eneco.2016.05.012.

[27] Denholm P, Hand M. Grid flexibility and storage required to achieve very high penetration of variable renewable electricity. Energy Policy 2011;39:1817-30. doi:10.1016/j.enpol.2011.01.019.

[28] IEA-ETSAP, IRENA. Electricity storage. 2012.

[29] International Energy Agency. Electricity in a climate constrained world. Paris, France: 2012.

[30] EPRI. Electricity Energy Storage Technology Options- A white paper primer on 
Applications, Costs and Benefits 2010.

[31] Rohit AK, Devi KP, Rangnekar S. An overview of energy storage and its importance in Indian renewable energy sector: Part I - Technologies and Comparison. J Energy Storage 2017;13:10-23. doi:10.1016/j.est.2017.06.005.

[32] Ould Amrouche S, Rekioua D, Rekioua T, Bacha S. Overview of energy storage in renewable energy systems. Int J Hydrogen Energy 2016;41:20914-27. doi:10.1016/j.ijhydene.2016.06.243.

[33] Gallo AB, Simões-Moreira JR, Costa HKM, Santos MM, Moutinho dos Santos E. Energy storage in the energy transition context: A technology review. Renew Sustain Energy Rev 2016;65:800-22. doi:10.1016/j.rser.2016.07.028.

[34] Akhil AA, Huff G, Currier AB, Kaun BC, Rastler DM, Chen SB, et al. DOE / EPRI 2013 Electricity Storage Handbook in Collaboration with NRECA 2013.

[35] Deane JP, Ó Gallachóir BP, McKeogh EJ. Techno-economic review of existing and new pumped hydro energy storage plant. Renew Sustain Energy Rev 2010;14:1293-302. doi:http://dx.doi.org/10.1016/j.rser.2009.11.015.

[36] Ming Z, Kun Z, Daoxin L. Overall review of pumped-hydro energy storage in China: Status quo, operation mechanism and policy barriers. Renew Sustain Energy Rev 2013;17:35-43. doi:http://dx.doi.org/10.1016/j.rser.2012.05.024.

[37] Fitzgerald N, Lacal Arántegui R, McKeogh E, Leahy P. A GIS-based model to calculate the potential for transforming conventional hydropower schemes and non-hydro reservoirs to pumped hydropower schemes. Energy 2012;41:483-90.

[38] Gimeno-gutiérrez M, Lacal-arántegui R. Assessment of the European potential for pumped hydropower energy storage storage potential. 2013. doi:10.2790/86815.

[39] Pickard WF. The history, present state, and future prospects of underground pumped hydro for massive energy storage. Proc IEEE 2012;100:473-83.

[40] Yang C-J, Jackson RB. Opportunities and barriers to pumped-hydro energy storage in the 
United States. Renew Sustain Energy Rev 2011;15:839-44.

doi:http://dx.doi.org/10.1016/j.rser.2010.09.020.

[41] Després J, Mima S, Kitous A, Criqui P, Hadjsaid N, Noirot I. Storage as a flexibility option in power systems with high shares of variable renewable energy sources: a POLESbased analysis. Energy Econ 2017;64:638-50. doi:10.1016/j.eneco.2016.03.006.

[42] Krajačić G, Lončar D, Duić N, Zeljko M, Lacal Arántegui R, Loisel R, et al. Analysis of financial mechanisms in support to new pumped hydropower storage projects in Croatia. Appl Energy 2013;101:161-71. doi:10.1016/j.apenergy.2012.07.007.

[43] Tam SW, Blomquist C a., Kartsounes GT. Underground Pumped Hydro Storage-An Overview. Energy Sources 1979;4:329-51. doi:10.1080/00908317908908068.

[44] Gordon JL. Parametric analysis of pump-turbine sites. 2009 IEEE Electr Power Energy Conf EPEC 2009 2009:1-6. doi:10.1109/EPEC.2009.5420906.

[45] Black \& Vetch Holding Company. Cost and Performance data for Power Generation Technologies. 2012.

[46] Madlener R, Specht JM. An Exploratory Economic Analysis of Underground PumpedStorage Hydro Power Plants in Abandoned Coal Mines February 2013 Institute for Future Energy Consumer Needs and Behavior ( FCN ). Aachen, Germany: 2013.

[47] Gonzalez A, Gallachoir B, McKeogh E. Study of Electricity Storage Technologies and thier Potential to Address Wind Energy Intermittency in Ireland. 2004.

[48] Succar S, Williams R. Compressed Air Energy Storage : Theory, Resources , And Applications For Wind Power Acknowledgments. Princet Environ Inst Princet Univ Energy Syst Anal Gr 2008.

[49] Barnes FS, Levine JG. Large Energy Storage Systems Handbook. CRC Press; 2011.

[50] Calaminus. Innovative adiabatic compressed air energy storage system of EnBW in Lower Saxony. 2nd Int. Renew. Energy Storage Conf. (IRES II), Bonn, Germany: 2007. 
[51] Wilson IAG, McGregor PG, Hall PJ. Energy storage in the UK electrical network: Estimation of the scale and review of technology options. Energy Policy 2010;38:4099106. doi:http://dx.doi.org/10.1016/j.enpol.2010.03.036.

[52] EPRI. Wind Power Integration : Energy Storage for Firming and Shaping. Palo Alto, CA: 2005.

[53] EPRI-DOE. Handbook of Energy Storage for Transmission \& Distribution Applications. Palo Alto, CA, Washington, DC: 2003.

[54] Steward D, Saur G, Penev M, Ramsden T. Lifecycle Cost Analysis of Hydrogen Versus Other Technologies for Electrical Energy Storage 2009.

[55] Zakeri B, Syri S. Electrical energy storage systems: A comparative life cycle cost analysis. Renew Sustain Energy Rev 2015;42:569-96. doi:10.1016/j.rser.2014.10.011.

[56] Chen H, Cong TN, Yang W, Tan C, Li Y, Ding Y. Progress in electrical energy storage system: A critical review. Prog Nat Sci 2009;19:291-312. doi:10.1016/j.pnsc.2008.07.014.

[57] Klumpp F. Potential for large scale energy storage technologies - Comparison and ranking including an outlook to 2030. Energy Procedia 2015;73:124-35. doi:10.1016/j.egypro.2015.07.659.

[58] Denholm P, Kulcinski G. Life cycle energy requirements and greenhouse gas emissions from large sacle energy storage systems.pdf 2004.

[59] Safaei H, Keith DW, Hugo RJ. Compressed air energy storage (CAES) with compressors distributed at heat loads to enable waste heat utilization. Appl Energy 2013;103:165-79. doi:10.1016/j.apenergy.2012.09.027.

[60] Zhen G, Lu X, Kumar G, Bakonyi P, Xu K, Zhao Y. Microbial electrolysis cell platform for simultaneous waste biorefinery and clean electrofuels generation: Current situation, challenges and future perspectives. Prog Energy Combust Sci 2017;63:119-45. doi:10.1016/j.pecs.2017.07.003. 
[61] Wang M, Wang Z, Gong X, Guo Z. The intensification technologies to water electrolysis for hydrogen production - A review. Renew Sustain Energy Rev 2014;29:573-88. doi:10.1016/j.rser.2013.08.090.

[62] International Energy Agency. Hydrogen Production and Storage: R\&D Priorities and Gaps. vol. 13. 2006. doi:10.1016/0360-3199(88)90106-1.

[63] Melaina MW, Antonia O, Penev M. Blending Hydrogen into Natural Gas Pipeline Networks : A Review of Key Issues Blending Hydrogen into Natural Gas Pipeline Networks : A Review of Key Issues 2013:131. doi:10.2172/1068610.

[64] Carr S, Premier GC, Guwy AJ, Dinsdale RM, Maddy J. Hydrogen storage and demand to increase wind power onto electricity distribution networks. Int J Hydrogen Energy 2014;39:10195-207. doi:10.1016/j.ijhydene.2014.04.145.

[65] Ozarslan A. Large-scale hydrogen energy storage in salt caverns. Int J Hydrogen Energy 2012;37:14265-77. doi:10.1016/j.ijhydene.2012.07.111.

[66] Michalski J, Bünger U, Crotogino F, Donadei S, Schneider GS, Pregger T, et al. Hydrogen generation by electrolysis and storage in salt caverns: Potentials, economics and systems aspects with regard to the German energy transition. Int J Hydrogen Energy 2017;42:13427-43. doi:10.1016/j.ijhydene.2017.02.102.

[67] Tarkowski R. Perspectives of using the geological subsurface for hydrogen storage in Poland. Int J Hydrogen Energy 2017;42:347-55. doi:10.1016/j.ijhydene.2016.10.136.

[68] Iordache I, Schitea D, Gheorghe A V., Iordache M. Hydrogen underground storage in Romania, potential directions of development, stakeholders and general aspects. Int $\mathrm{J}$ Hydrogen Energy 2014;39:11071-81. doi:10.1016/j.ijhydene.2014.05.067.

[69] Amid A, Mignard D, Wilkinson M. Seasonal storage of hydrogen in a depleted natural gas reservoir. Int J Hydrogen Energy 2016;41:5549-58. doi:10.1016/j.ijhydene.2016.02.036.

[70] Lord AS, Kobos PH, Borns DJ. Geologic storage of hydrogen: Scaling up to meet city transportation demands. Int J Hydrogen Energy 2014;39:15570-82. doi:10.1016/j.ijhydene.2014.07.121. 
[71] Schiebahn S, Grube T, Robinius M, Tietze V, Kumar B, Stolten D. Power to gas: Technological overview, systems analysis and economic assessment for a case study in Germany. Int J Hydrogen Energy 2015;40:4285-94. doi:10.1016/j.ijhydene.2015.01.123.

[72] Marchenko O V., Solomin S V. The future energy: Hydrogen versus electricity. Int J Hydrogen Energy 2015;40:3801-5. doi:10.1016/j.ijhydene.2015.01.132.

[73] Ibrahim H, Ilinca A, Perron J. Energy storage systems - Characteristics and comparisons. Renew Sustain Energy Rev 2008;12:1221-50. doi:http://dx.doi.org/10.1016/j.rser.2007.01.023.

[74] Kousksou T, Bruel P, Jamil A, El Rhafiki T, Zeraouli Y. Energy storage: Applications and challenges. Sol Energy Mater Sol Cells 2014;120:59-80. doi:10.1016/j.solmat.2013.08.015.

[75] Guinot B, Champel B, Montignac F, Lemaire E, Vannucci D, Sailler S, et al. Technoeconomic study of a PV-hydrogen-battery hybrid system for off-grid power supply: Impact of performances' ageing on optimal system sizing and competitiveness. Int J Hydrogen Energy 2015;40:623-32. doi:10.1016/j.ijhydene.2014.11.007.

[76] Ferrero D, Gamba M, Lanzini A, Santarelli M. Power-to-Gas Hydrogen: Technoeconomic Assessment of Processes towards a Multi-purpose Energy Carrier. Energy Procedia 2016;101:50-7. doi:10.1016/j.egypro.2016.11.007.

[77] Bakonyi P, Buitrón G, Valdez-Vazquez I, Nemestóthy N, Bélafi- Bakó K. A novel gas separation integrated membrane bioreactor to evaluate the impact of self-generated biogas recycling on continuous hydrogen fermentation. Appl Energy 2017;190:813-23. doi:10.1016/j.apenergy.2016.12.151.

[78] Kumar G, Bakonyi P, Periyasamy S, Kim SH, Nemestóthy N, Bélafi-Bakó K. Lignocellulose biohydrogen: Practical challenges and recent progress. Renew Sustain Energy Rev 2015;44:728-37. doi:10.1016/j.rser.2015.01.042.

[79] Kumar G, Bakonyi P, Zhen G, Sivagurunathan P, Koók L, Kim SH, et al. Microbial electrochemical systems for sustainable biohydrogen production: Surveying the 
experiences from a start-up viewpoint. Renew Sustain Energy Rev 2017;70:589-97. doi:10.1016/j.rser.2016.11.107. 
